University of Montana

ScholarWorks at University of Montana

10-2005

\title{
Evolution of Sexual Dimorphism and Male Dimorphism in the Expression of Beetle Horns: Phylogenetic Evidence for Modularity, Evolutionary Lability, and Constraint
}

\author{
Douglas J. Emlen \\ University of Montana - Missoula, Doug.Emlen@mso.umt.edu \\ John Hunt \\ University of Montana - Missoula, john.hunt@mso.umt.edu \\ Leigh W. Simmons
}

Follow this and additional works at: https://scholarworks.umt.edu/biosci_pubs

Part of the Biology Commons

Let us know how access to this document benefits you.

\section{Recommended Citation}

Emlen, Douglas J.; Hunt, John; and Simmons, Leigh W., "Evolution of Sexual Dimorphism and Male Dimorphism in the Expression of Beetle Horns: Phylogenetic Evidence for Modularity, Evolutionary Lability, and Constraint" (2005). Biological Sciences Faculty Publications. 204.

https://scholarworks.umt.edu/biosci_pubs/204

This Article is brought to you for free and open access by the Biological Sciences at ScholarWorks at University of Montana. It has been accepted for inclusion in Biological Sciences Faculty Publications by an authorized administrator of ScholarWorks at University of Montana. For more information, please contact scholarworks@mso.umt.edu. 


\title{
Evolution of Sexual Dimorphism and Male Dimorphism in the Expression of Beetle Horns: Phylogenetic Evidence for Modularity, Evolutionary Lability, and Constraint
}

\author{
Douglas J. Emlen, ${ }^{1, *}$ John Hunt, ${ }^{2, \dagger}$ and Leigh W. Simmons ${ }^{3, *}$
}

1. Division of Biological Sciences, University of Montana, Missoula, Montana 59812;

2. School of Biological, Earth and Environmental Sciences, University of New South Wales, Sydney 2052, New South Wales, Australia;

3. Evolutionary Biology Research Group, School of Animal Biology, University of Western Australia, Nedlands, Western Australia 6009, Australia

ABStRACt: Beetle horns are enlarged outgrowths of the head or thorax that are used as weapons in contests over access to mates. Horn development is typically confined to males (sexual dimorphism) and often only to the largest males (male dimorphism). Both types of dimorphism result from endocrine threshold mechanisms that coordinate cell proliferation near the end of the larval period. Here, we map the presence/absence of each type of dimorphism onto a recent phylogeny for the genus Onthophagus (Coleoptera: Scarabaeidae) to explore how horn development has changed over time. Our results provide empirical support for several recent predictions regarding the evolutionary lability of developmental thresholds, including uncoupled evolution of alternative phenotypes and repeated fixation of phenotypes. We also report striking evidence of a possible developmental constraint. We show that male dimorphism and sexual dimorphism map together on the phylogeny; whenever small males have horns, females also have horns (and vice versa). We raise the possibility that correlated evolution of these two phenomena results from a shared element in their endocrine regulatory mechanisms rather than a history of common selection pressures. These results illustrate the type of insight that can be gained only from the integration of developmental and evolutionary perspectives.

Keywords: evolution, developmental switch, threshold mechanism, male dimorphism, sexual dimorphism, polyphenism.

\footnotetext{
* Corresponding author; e-mail: doug.emlen@mso.umt.edu.

E-mail: john.hunt@unsw.edu.au.

E-mail: 1simmons@cyllene.uwa.edu.au.
}

Am. Nat. 2005. Vol. 166, pp. S42-S68. (c) 2005 by The University of Chicago. 0003-0147/2005/1660\$4-40979\$15.00. All rights reserved.
Explicit incorporation of developmental biological information into the study of evolution has brought unprecedented resolution to the questions of how populations and species change over time (e.g., Alberch 1982; Bonner 1982; Hall 1992; Hanken and Thorogood 1993; Akam et al. 1994; Raff 1996; Carroll et al. 2001). The mechanistic processes of ontogeny translate expressed genes into expressed phenotypes and so determine the nature of selectable variation (Alberch 1982; Riska 1986; Pigliucci et al. 1996; Dover 2000; Stern 2000; West-Eberhard 2003; Schlosser and Wagner 2004). Indeed, heritable changes in morphological phenotypes arise from modifications to components of development. Consequently, the most complete reconstruction of morphological character evolution entails knowledge of both how the focal phenotype has changed over time and how underlying aspects of the development of that character have changed to yield the observed transformations in expressed phenotypes. However, only rarely is it possible to combine these traditionally disparate perspectives for the same focal character.

One class of developmental mechanisms-called "developmental switch" or "threshold" mechanisms-is especially amenable to the integration of development with evolution (West-Eberhard 1989, 1992, 2003). Threshold mechanisms permit a single genome to produce two or more alternative morphologies, often in response to an environmental cue (e.g., seasonal, dispersal, or caste polyphenisms, male dimorphism; reviewed in Harrison 1980; Roff 1986, 1996; Gross 1996; Greene 1999). Threshold mechanisms are relatively easy to recognize within natural populations (they are among a small number of means by which dimorphic or bimodal distributions of phenotypes are produced; see Wilson 1953, 1971; Harrison 1979; Roff 1986, 1996; Eberhard and Gutierrez 1991; Kawano 1995a, 1995b; Tomkins and Simmons 1996; Danforth and Desjardins 1999; Hanley 2001; Rowland 2003), they are relatively easy to study physiologically (reviewed in Nijhout and Wheeler 1982; Hardie and Lees 1985; Moore 1991; Zera and Denno 1997; Nijhout 1999a; Dingle 2002; Hart- 
felder and Emlen 2004), and they are predicted to have major consequences for subsequent evolution of populations or species that incorporate them (reviewed in WestEberhard 1989, 1992, 2003; Hazel et al. 1990; Moran 1992; Roff 1994, 1996; Danforth and Desjardins 1999; Emlen and Nijhout 2000; Brockmann 2001).

This study focuses on the evolution of two threshold mechanisms regulating the expression of horns in the beetle genus Onthophagus (Coleoptera: Scarabaeidae): one generating male dimorphism (large males produce horns; smaller males do not) and the other generating sexual dimorphism (males produce horns; females do not). Beetle horns are enlarged outgrowths of the head or thorax; they are generally expressed only in males (e.g., Darwin 1871; Paulian 1935; Arrow 1951; Eberhard 1980; Enrödi 1985), and in all cases studied to date, they are used by males in intraspecific battles over reproductive access to females (e.g., Eberhard 1979, 1987; Goldsmith 1987; Siva-Jothy 1987; Conner 1988; Otronen 1988; Rasmussen 1994; Emlen 1997a; Moczek and Emlen 2000; Hunt and Simmons 2001).

A recent DNA sequence-based phylogeny for $48 \mathrm{On}$ thophagus species reveals prolific divergence in the morphologies of beetle horns (Emlen et al. 2005). In most of the included species, males produce some form of horn(s). However, several species do not have horns, and in a surprising number of species, both males and females produce horns. In addition, onthophagine horns vary interspecifically in size, shape, and even physical location, extending from any of five locations on the head or thorax. This evolutionary radiation of beetle horns forms the backdrop for our comparative study of evolution in the mechanisms regulating horn development.

Beetle horn development has been studied extensively in Onthophagus taurus (Emlen and Nijhout 1999, 2000, 2001; Emlen 2000, 2005; Moczek and Nijhout 2002; Emlen and Allen 2004), and from these studies, we have working models for the endocrine regulation of both male and sexual dimorphism in horn expression. Importantly, both of these mechanisms have pronounced and predictable consequences for the distribution of phenotypic variation among individuals (figs. 1, 2) and therefore can be recognized from samples of natural beetle populations (by the characteristic shapes of the resulting horn length/body size scaling relationships [allometries; sensu Cock 1966; LaBarbera 1989]). We report here on measurements of horn lengths and body sizes collected from samples of natural populations of 31 of the species included in the phylogeny. These include measures of all of the different horn types, of horns in both males and females, and in several cases, of multiple horns within the same species. By using the shape of the resulting horn length/body size scaling relationships to infer the existence of developmen- tal thresholds regulating horn expression, we are able to map the presence/absence of each of these threshold mechanisms onto a reconstruction of horn evolution and begin to explore how both horns and horn development have changed over the history of this genus.

Results from this study provide empirical support for several recent predictions regarding the evolution of threshold traits (West-Eberhard 1989, 1992, 2003; Raff 1996; Nijhout 1999a). First, threshold mechanisms permit unusually independent evolution (e.g., divergence) of the phenotypic alternatives. Second, thresholds constitute a form of developmental modularity such that the threshold mechanism can evolve independently from either of the downstream phenotypes regulated by the threshold (independent evolution of regulation and form) and such that novel phenotypes are dissociable; they can be subsumed within, or uncoupled from, an existing regulatory process. Finally, our analyses show that lineages can lose the capacity for developmental flexibility when one or the other developmental alternative is fixed.

In addition, our results yield the surprising finding that the mechanisms regulating male dimorphism and sexual dimorphism are not independent from one another. We show that male dimorphism and sexual dimorphism map together on the phylogeny and that in dimorphic Onthophagus species, small males always produce rudimentary horn morphologies that are equivalent in length to those of females. We raise the possibility that correlated evolution of these two phenomena results from a shared element in their endocrine regulatory mechanisms; both mechanisms appear to utilize a pulse of the same hormone (ecdysteroid) at the same time (Emlen and Nijhout 1999). We conclude with the suggestion that male dimorphism in horn expression arose through the co-option of an existing mechanism for sexual dimorphism.

\section{Background: The Development of Beetle Horns}

Beetles in the genus Onthophagus are subterranean dung beetles. Their larvae develop in isolation inside tunnels belowground, where they feed on dung that has been provisioned by the parents (Fabre 1899; Main 1922; Halffter and Matthews 1966; Halffter and Edmonds 1982; Hunt and Simmons 2000, 2002). All scarab beetles pass through three larval stages, or instars, and a pupal stage before they molt into adults (Crowson 1981). By the end of their third (and final) larval instar, animals have reached their maximum overall body size, and at this time they cease feeding, empty their guts, and begin the process of metamorphic transformation from a larval to a pupal morphology (described for Onthophagus in Emlen and Nijhout 1999, 2001; Emlen 2000, 2005; Emlen and Allen 2004).

Beetle larvae bear little resemblance to pupae or adults 

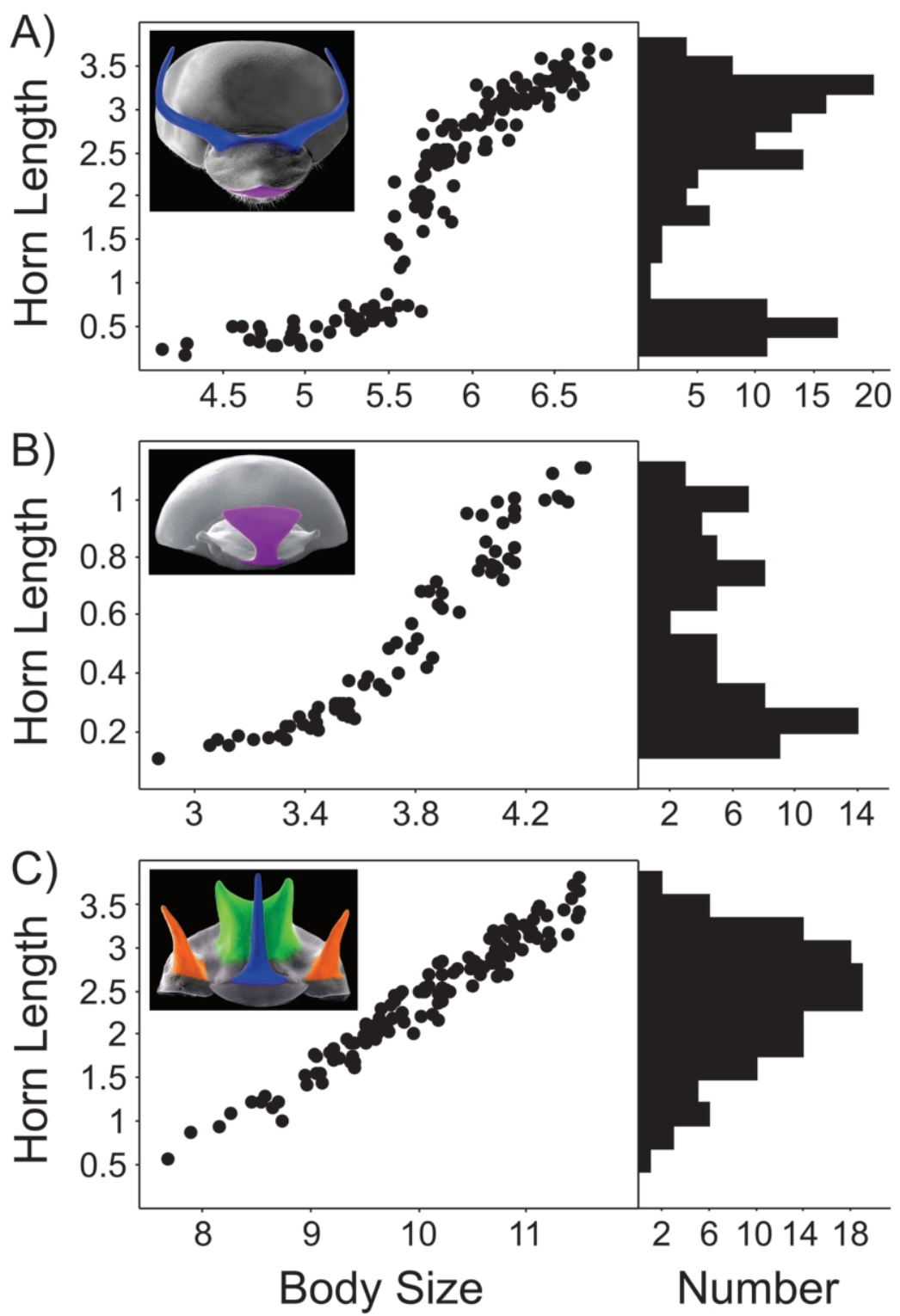

Figure 1: Male dimorphism in beetle horn expression. Horns with dimorphic expression have nonlinear scaling relationships between horn length and body size (prothorax width), either sigmoid $(A)$ or curved/bent $(B)$. This produces natural populations with bimodal frequency distributions of male horn lengths (histograms). Horns lacking male dimorphism (i.e., monomorphic) have linear scaling relationships $(C)$ and unimodal frequency distributions of male horn lengths. Data shown for head horns (H1, blue) of Onthophagus taurus $(A)$, head horns (H3, purple) of $O$. sharpi $(B)$, and thorax horns (H4, green) of O. pentacanthus $(C)$.

(e.g., no eyes, antennae, wings, genitalia, or horns). As in most holometabolous (metamorphic) insects, the cells that will form each of these adult structures are set aside early in larval development, and these clusters of cells (called "imaginal discs"; sensu Svácha 1992; Truman and Riddiford 2002) remain relatively dormant until the end of the larval feeding period (e.g., Huet 1980; Quennedey and Quennedey 1990; Connat et al. 1991). When larvae begin to purge their guts in preparation for metamorphosis, these clusters of cells exhibit a rapid burst of proliferative growth, and each imaginal disc grows to form a distinct morphological structure (for reviews of insect imaginal disc growth, see Williams 1980; Fristrom and Fristrom 1993; Milan et al. 1996; Nijhout and Wheeler 1996; Truman and Riddiford 1999, 2002).

As these nascent structures grow, they remain trapped 


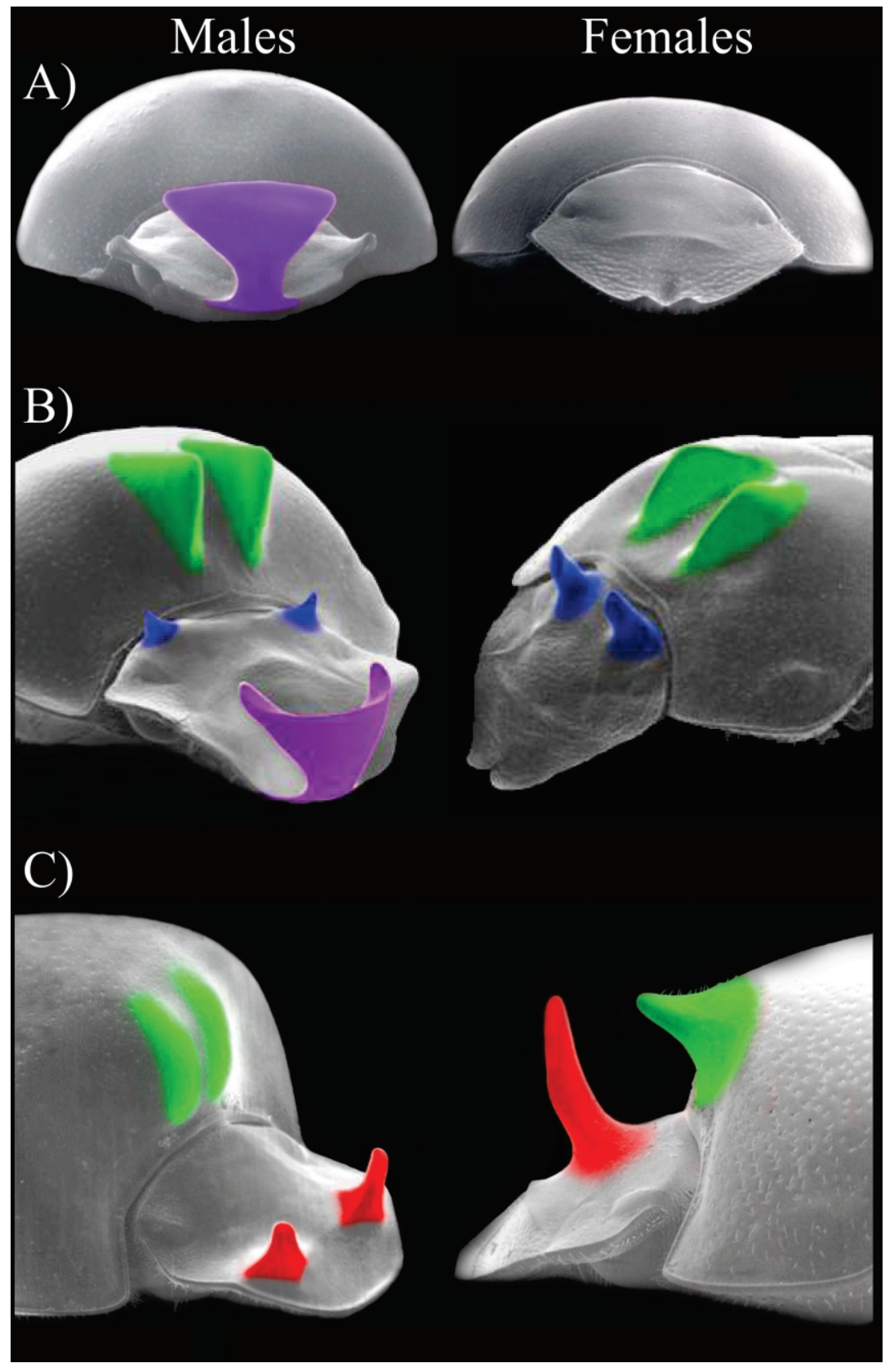

Figure 2: Sexual dimorphism in beetle horn expression. Most horn types in most species are produced only by males (sexual dimorphism for presence/absence of the horn; purple horns in $A, B$ ). However, multiple times during the history of this genus, sexual dimorphism was lost because of the gain of horns in females (sexual monomorphism for horn presence; blue, red, and green horns in $B$, C). Sexually dimorphic horns and sexually monomorphic horns can occur simultaneously in the same species $(B)$, so dimorphic expression was scored separately for each horn type. In all cases but one, female horns were the same basic shape and in the same physical location as corresponding horns expressed in males. The single exception involved a head horn $(\mathrm{H} 2$, red) of females that was qualitatively different from the corresponding horn of males $(C)$. Species illustrated: Onthophagus sharpi $(A)$, O. praecellens (B), O. sagittarius $(C)$. 
within the outer larval-shaped exoskeleton. Consequently, they form as intricately folded bundles of epidermal tissue (fig. 3). Late-stage final instar larvae (or "pre-pupae") are actually in the process of growing most of the adult structures. When the animal molts to a pupa, these folded structures unfurl to take their full form. Insect pupae have all of the major structures of the adult, and in most cases, these structures have already reached their final adult dimensions (for reviews of insect metamorphosis, see $\mathrm{Ni}$ jhout 1994; Riddiford 1994, 1996; Gilbert et al. 1996; Truman and Riddiford 1999, 2002; Emlen and Allen 2004).

For each imaginal disc, the rate and duration of cell proliferation, as well as changes in cell size, specify the final dimensions of the resulting adult structure (Conlon and Raff 1999; Edgar 1999; Stern and Emlen 1999; Weinkove and Leevers 2000; Bryant 2001; Johnston and Gallant 2002; Emlen and Allen 2004). These processes are sensitive to nutrition, larval growth, and individual body size (Edgar 1999; Kawamura et al. 1999; Stern and Emlen 1999; Bryant 2001; Nijhout and Grunert 2003; Stern 2003) so that the final sizes of adult appendages scale closely with amongindividual variation in overall body size: large individuals produce larger eyes, legs, and wings than smaller individuals (Stern and Emlen 1999; Emlen and Nijhout 2000; Emlen and Allen 2004).

Beetle horns form in the same manner as these other insect structures-as localized clusters of epidermal cells that undergo a brief period of rapid proliferation at the very end of the larval period (Emlen and Nijhout 1999, 2001; Emlen 2000, 2005). In Onthophagus taurus, the growing horns form as a pair of densely folded masses of epidermal tissue that remain trapped beneath the larval head capsule until pupation (fig. $3 A$ ).

Threshold mechanisms regulating beetle horn expression operate immediately before the period of horn growth and use hormones to either permit or prevent proliferation in the regional clusters of epidermal cells that will form the respective horns (Emlen and Nijhout 1999, 2001; Emlen and Allen 2004). These mechanisms result in dramatically altered patterns of scaling in large and small males (male dimorphism; fig. 1) or between males and females (sexual dimorphism).

\section{Developmental Basis of a Threshold}

Developmental thresholds couple gene expression with encountered levels of an environmental cue (Nijhout 1994, 1999a; Evans and Wheeler 2001). Relevant cues can include any number of environmental features as well as genetic factors. In all cases, detected levels of these cues are translated into levels of an internal circulating hormone signal, and it is the levels of this signal (above or below a critical threshold level) that determine the pattern of development (for recent reviews of threshold mechanisms [including sexual dimorphism], see Hews and Moore 1995; Owens and Short 1995; Zera and Denno 1997; Kimball and Ligon 1999; Nijhout 1999a; Evans and Wheeler 2001; Dingle 2002; West-Eberhard 2003; Hartfelder and Emlen 2004; Emlen 2005).

Hormone signals are substances that are globally cir-

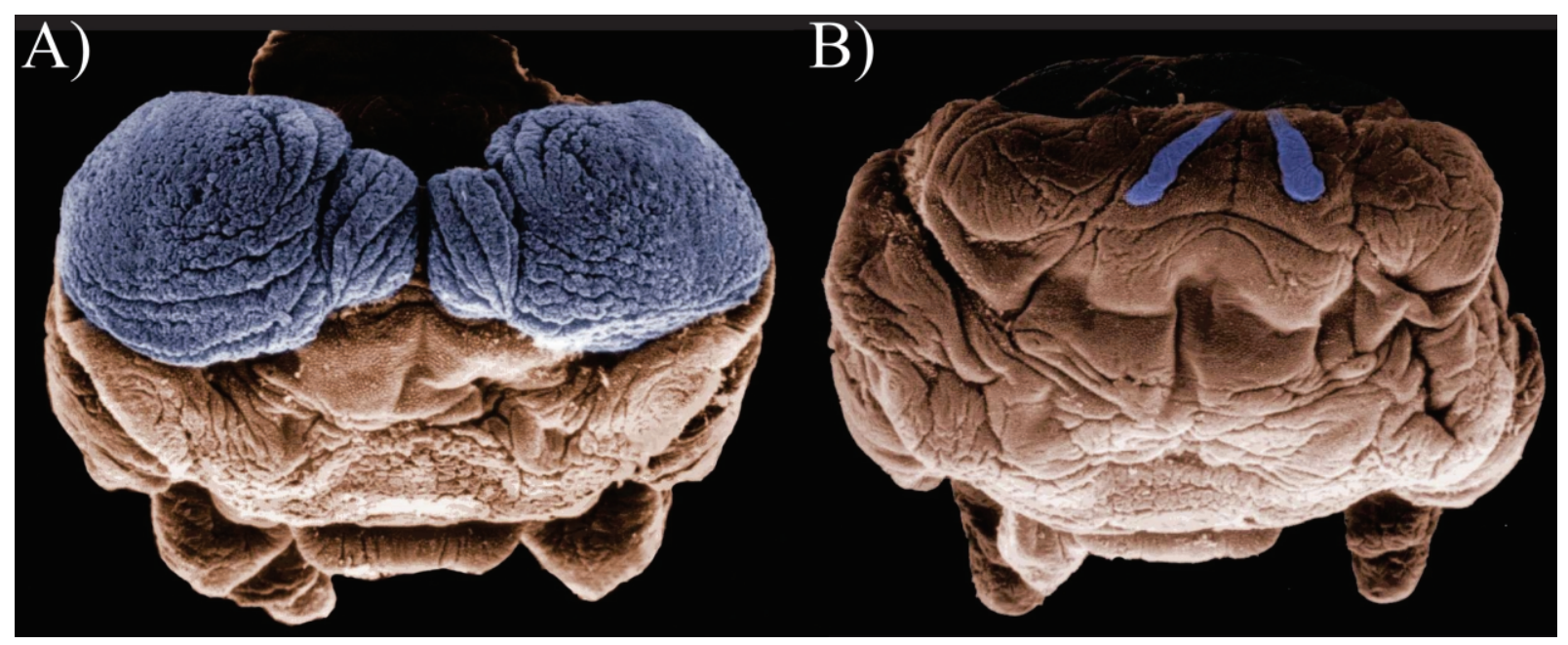

Figure 3: SEM photographs of horned $(A)$ and hornless $(B)$ male prepupae of Onthophagus taurus. In both cases, the outer larval head capsule has been removed, revealing the newly formed epidermis of the pupal head. Horn tissues are shown in blue. Horn cells undergo a burst of proliferation in large males that results in the production of a pair of (folded) tubes of epidermis. This burst of cell proliferation does not occur in small males or females (not shown). 
culated within developing animals and whose levels are sensitive to conditions encountered by those animals as they grow: individuals exposed to one set of conditions have lower concentrations of the hormone signal than other individuals exposed to a different set of conditions. Thus, the hormone signal constitutes the mechanistic link between external circumstances encountered by an individual and internal patterns of gene expression and tissue growth and development.

Animals generally have a sensitive period, a brief physiological period when levels of a circulating hormone signal are assessed ${ }^{1}$ relative to the critical threshold level. Cells in specific tissues (e.g., cell clusters that produce horns) are thought to express receptors for the hormone signal during the sensitive period, and the number and type of receptors expressed, including their binding affinities for the particular hormone, determine the threshold concentration of the hormone signal required to elicit a response (e.g., Nijhout 1999a).

Levels of the hormone signal above (or below) this critical threshold level elicit an all-or-none response cascade, often via pulses of secondary hormones and/or through the action of transcription factors and genetic patterning cascades (reviewed in Nijhout 1999a; Evans and Wheeler 2001; Hartfelder and Emlen 2004; Emlen 2005). For many insects, these downstream response cascades can direct the development of complex suites of morphological, physiological, and behavioral traits.

Thus, the basic ingredients of a developmental threshold (or switch) mechanism include some environmentresponsive sensory apparatus (sensor), a circulating hormone signal that is responsive to environmental inputs via the sensor, a sensitive period when target cells respond to the hormone signal, a threshold level of cellular sensitivity to the hormone signal, and secondary hormones and/or transcription factors that direct the physiological and genetic response cascades that coordinate the development of the phenotypic alternatives. The processes involved with detecting relevant cues and translating this information into circulating levels of the hormone signal can be considered to be "upstream" to the threshold mechanism. "Downstream" processes include all of the cellular patterning and growth, physiology, and behavior that are activated once the response is triggered. At that point, the resultant phenotype is, in effect, determined (summarized for O. taurus in fig. 4).

\footnotetext{
${ }^{1}$ We use the definition of West-Eberhard (2003, p. 442), where "assessment" occurs whenever a particular response correlates consistently with some environmental variable.
}

\section{Threshold Mechanism 1: Male Dimorphism}

Horn lengths depend on body size (horns scale positively with body size [allometry]). Male dimorphism in horn expression involves an additional level of body sizedependent regulation of horn growth: males smaller than a threshold body size appear to be switched to an altered, dramatically reduced pattern of horn growth. The sizes of horns in these small males scale according to a very different relationship with a much shallower slope than horn sizes in larger males (figs. 1, 4). For this article, we call these males "hornless" to distinguish them from males with fully developed horns, although most of these individuals possess rudimentary versions of the horns.

Environmental factors-most notably, larval nutrition-influence the growth and final size of individuals (Emlen 1994, 1996, 1997b; Hunt and Simmons 1997, 2002; Moczek 1998, 2002; Moczek and Emlen 1999; Kotiaho et al. 2003), and these same factors appear to cue the threshold-regulating male horn expression (Emlen and Nijhout 1999, 2001; Emlen 2000, 2005). Juvenile hormone (JH) is the signal hormone of this mechanism; levels of $\mathrm{JH}$ are known to be sensitive to larval nutrition and to larval growth in insects (e.g., Strambi et al. 1984; Hartfelder 1990; Rachinsky and Hartfelder 1990; Wheeler 1991; Rankin et al. 1997; Hartfelder and Engels 1998; Schulz et al. 2002), as are levels of $\mathrm{JH}$ esterase, an enzyme that breaks down circulating JH (Rachinsky and Hartfelder 1990; Browder et al. 2001; Tu and Tatar 2003). Thus, JH is an effective link between external conditions related to larval growth and internal processes that coordinate the development of organs and tissues, including the horns (Nijhout 1994, 1999a; Stern and Emlen 1999; Emlen and Allen 2004; Emlen 2005). In Onthophagus beetles, by the end of the larval feeding period, levels of circulating $\mathrm{JH}$ appear to be lower in large individuals than in smaller individuals (Emlen and Nijhout 2001; fig. 4A, 4B).

Male larvae have a sensitive period just before the end of the larval feeding period, as animals reach their largest body sizes, and just before the onset of horn growth (Emlen and Nijhout 2001; vertical gray bar, fig. $4 A, 4 B$ ). The cells that will form the horns are sensitive to circulating levels of $\mathrm{JH}$ at this time, and animals with levels of $\mathrm{JH}$ above a critical threshold level (i.e., small males) adopt a hornless developmental fate (fig. 4B). These small animals have a brief pulse of ecdysteroid hormone that occurs at this time and that is not present in large males (Emlen and Nijhout 1999, 2001; red arrow, fig. 4B). Ecdysteroids are known to reprogram the developmental fates of tissues by switching downstream patterns of gene expression (reviewed in Bollenbacher 1988; Gilbert 1989; Berger et al. 1992; Nijhout 1994; Riddiford 1994, 1996; Gilbert et al. 1996; Truman and Riddiford 1999, 2002), and this pulse 
may suppress the development of horns in small males (possibly by altering the sensitivity of horn cells to $\mathrm{JH}$ during a second, later, sensitive period [the period described in Emlen and Nijhout 1999; Moczek and Nijhout 2002]).

Consequently, our model for the threshold mechanism generating male dimorphism in horn expression involves a signal hormone $(\mathrm{JH})$, a sensitive period (the end of the larval feeding period), a critical threshold of sensitivity to the signal hormone (that corresponds to a critical body size), and facultative production of a pulse of a secondary hormone known to switch downstream patterns of gene expression (summarized in fig. $4 A, 4 B$ ). The presence or absence of this ecdysteroid pulse is correlated with whether horn cells develop according to a pattern of pronounced horn growth, generating a steep and positive horn length/ body size scaling relationship, or according to a pattern of reduced horn growth, generating a much shallower scaling relationship between horn lengths and body size (figs. $3,4)$.

\section{Threshold Mechanism 2: Sexual Dimorphism}

We know less about the mechanism of sexual dimorphism, although several important points are clear. First, sex is likely to be chromosomally determined (the majority of studied scarabs, including Onthophagus [O. rectecornutus] have XY sex determination [ $2 \mathrm{n}=20$ ]; Venu et al. 2000; Moura et al. 2003). Second, females in O. taurus do not produce horns at any body size despite the fact that they vary in body size over the same range as males. Third, females appear to be insensitive to levels of $\mathrm{JH}$ that affect growth of the horns in males (e.g., perturbations to $\mathrm{JH}$ levels never induce females to produce horns, as they do with small males; Emlen and Nijhout 1999, 2001; Moczek and Nijhout 2002). Fourth, females show the same pulse of ecdysteroids that is observed in small males, and this pulse occurs at the same time, at the end of the larval feeding period (Emlen and Nijhout 1999). Finally, secre- tion of the ecdysteroid pulse is not connected with the attainment of a particular body size; all females of all sizes have the ecdysteroid pulse (Emlen and Nijhout 1999, 2001).

Our model for the threshold mechanism of sexual dimorphism in beetle horn expression is summarized in figure $4 A, 4 C$. Current evidence suggests that large males have the neutral, or default, pattern of horn growth (see "Methods" for justification), which results in the production of large horns that, in natural populations, scale positively with body size. Some unidentified process couples the sex (or some cue correlated with sex) of individuals with a facultative pulse of ecdysteroids during the sensitive period for regulation of horn growth, that is, at the end of the larval feeding period (vertical gray bar, fig. 4). The result of this process is that females produce a pulse of ecdysteroids not present in (large) males (red arrow, fig. $4 C$ ). As in the threshold mechanism described for male dimorphism, this pulse of ecdysteroids is correlated with the fate of horn cells: animals with this pulse (i.e., females) dispense with the burst of proliferative growth typical of horned males.

Both mechanisms (male and sexual dimorphism) resemble developmental thresholds described for other taxa (e.g., queen vs. worker development in ants [Wheeler and Nijhout 1983; Wheeler 1991] and bees [Rachinsky and Hartfelder 1990]; winged vs. wingless development in crickets [Zera and Holtmeier 1992; Zera and Denno 1997] and planthoppers [Iwanaga and Tojo 1986; Ayoade et al. 1999]; male vs. female ornament brightness in lizards [Hews and Moore 1995] and birds [Owens and Short 1995; Kimball and Ligon 1999]). In all of these cases, developmental thresholds permit a single genome (or similar genomes in the case of sexual dimorphism) to construct one of several different phenotypes by partially uncoupling gene expression in the downstream alternatives-different suites of genes and gene interactions contribute to the formation of each of the two alternative phenotypes (reviewed in Evans and Wheeler 2001; West-Eberhard 2003).

Figure 4: Endocrine regulation of male and sexual dimorphism in the beetle Onthophagus taurus. By the middle of the third larval instar, large and small males differ in circulating levels of juvenile hormone $(\mathrm{JH})$ : large males have lower concentrations than smaller males. JH levels are assessed during a brief sensitive period immediately before the cessation of feeding (vertical gray bar), and relatively large males have JH concentrations below the critical threshold (black horizontal line) at this time $(A)$. Cells in the developing horns of these individuals undergo a brief pulse of rapid proliferation during the prepupal period (blue curve), and these larvae mature into adult males with fully developed horns (insert). B, Small male larvae have $\mathrm{JH}$ concentrations above the threshold during the sensitive period, and these animals experience a brief pulse of a second hormone, ecdysone (red arrow in B). Ecdysone is known to initiate cascades of gene expression, and this tactic-specific pulse appears to affect the fate of horn cells such that they subsequently undergo only minimal proliferation. Small males mature into adults with only rudimentary horns (insert). $C$, Horn cells in female larvae appear to be insensitive to JH. However, females have the same ecdysteroid pulse as do small males, and this hormone pulse occurs during the same sensitive period (red arrow in C). Female larvae also mature into adults with only rudimentary horns (insert). Drawings illustrate larval (prepupal), pupal, and adult heads, with developing horns in blue (larval heads shown with head capsule removed). Note that horns in O. taurus females consist of an elevated ridge rather than a pair of bumps. Modified from work by Emlen and Nijhout (2001), Emlen and Allen (2004), and Emlen (2005). 


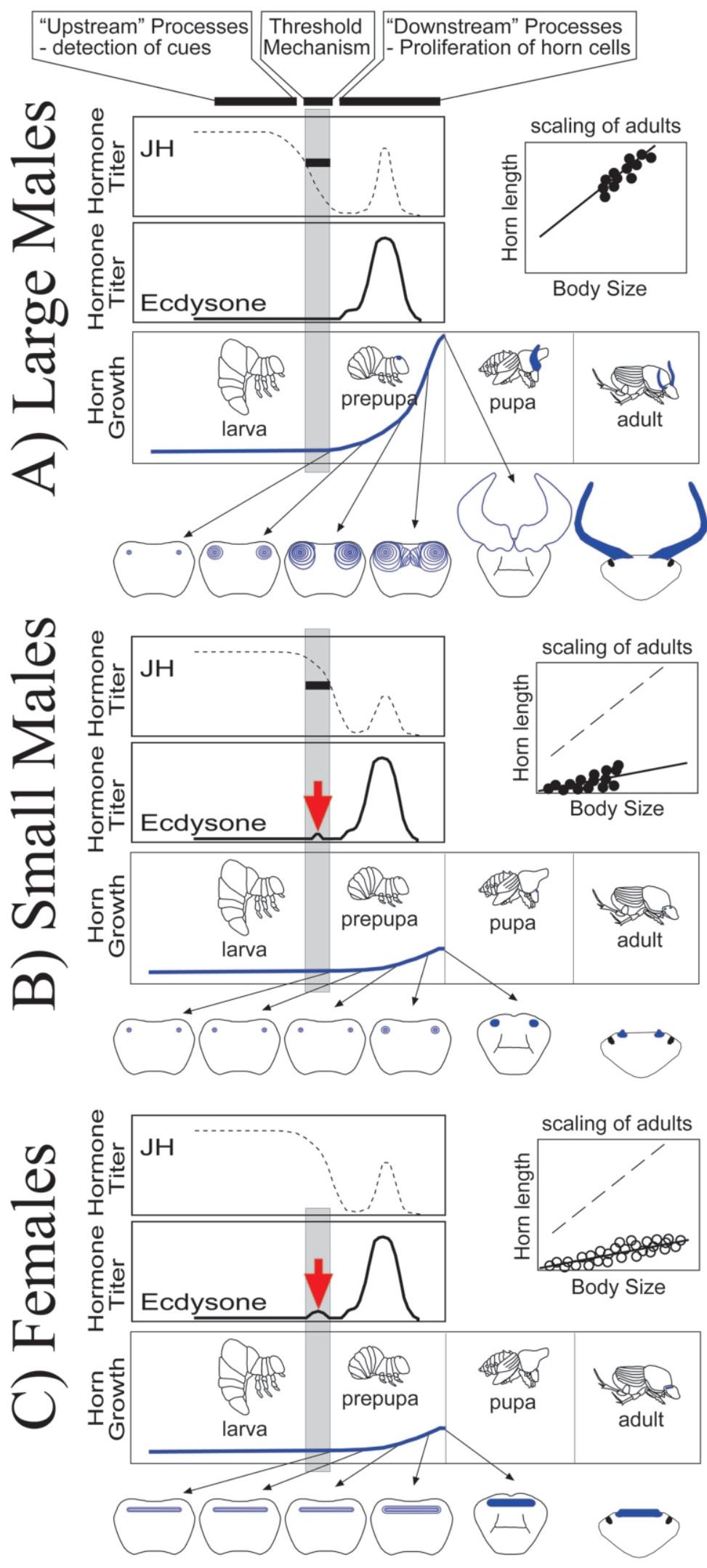


Consequently, developmental threshold mechanisms are predicted to minimize genetic correlations (e.g., pleiotropy) between the alternative phenotypes, facilitating the independent evolution of these forms and affecting the directions and nature of subsequent morphological evolution (West-Eberhard 2003). In the following sections, we begin to test these predictions for beetle horns by mapping both male and sexual dimorphism in horn expression onto a phylogenetic reconstruction of the history of the genus Onthophagus.

\section{Methods}

\section{Sampling of Taxa and Morphometric Measurements}

Horns in the beetle genus Onthophagus can arise from five distinct physical locations involving different segments and sclerites in the developing animals: the base of the head (vertex; H1, blue in all figures), the center of the head (frons; H2, red), the front of the head (clypeus; H3, purple), as well as from the center ( $\mathrm{H} 4$, green) and sides (H5, orange) of the thoracic pronotum. Because these reflect distinct regions of the larval epidermis and because it was possible for species to have horns at all possible combinations of these locations, we treated each physical location as a separate horn type (i.e., different characters and not alternative states for a single character; Emlen et al. 2005).

We were able to measure representative samples from natural populations of 31 of the 48 Onthophagus species included in the phylogeny of Emlen et al. (2005). Taxa included in this study are listed in table 1 . Horn lengths and body size (prothorax width) were measured for all horn types of all individuals using an ocular micrometer and/or a digital camera connected to a dissecting microscope with ScionImage software.

\section{Inferring Mechanism from Population Samples}

Quantifying Male Dimorphism. The incorporation of a developmental threshold into the expression of male horns results in an abrupt change in the slope of the scaling relationship between horn length and body size and in a bimodal frequency distribution of male horn lengths (Eberhard and Gutierrez 1991; Emlen and Nijhout 2000; Kotiaho and Tomkins 2001; fig. 1A, 1B). We scored male dimorphism in horn expression from visual examinations of scaling relationship shape, statistical tests for nonlinearity of the scaling relationship (Eberhard and Gutierrez 1991; Kotiaho and Tomkins 2001), and examinations of the frequency distributions of male horn lengths. For most of the male-dimorphic horn types included in this study, the scaling relationship between horn length and body size had a characteristic "broken," or sigmoid, shape (fig. 1A), and all of these were significantly nonlinear on both untransformed and log-transformed scales (see Tomkins et al. 2005). Horns in three species (H3, purple, in Onthophagus sharpi and $O$. praecellens and $\mathrm{H} 4$, green, in $O$. binodis) exhibited a different form of dimorphism, characterized by a curved or "bent" scaling relationship between horn length and body size (fig. 1B). All horns scored as male dimorphic exhibited bimodal frequency distributions for the length of that horn type in natural populations (e.g., fig. $1 A, 1 B$ ). In contrast, horns of males monomorphic for horn production had linear scaling relationships between horn length and body size (on both raw and/or $\log _{10}$-transformed scales) and unimodal natural frequency distributions of male horn lengths (e.g., fig. 1C).

We detected no evidence of female dimorphism (i.e., a body size-dependent switch in female horn expression). All female horns in this study exhibited linear scaling relationships between horn length and body size and had unimodal natural frequency distributions of horn lengths.

Quantifying Sexual Dimorphism. Sexual dimorphism can take many forms. In insects, sexual dimorphism in the expression of enlarged ornaments or weapons generally falls into two categories: dimorphism in the relative size of a structure and dimorphism in the presence/absence of a structure. Sexual dimorphism in relative trait size occurs in species in which both sexes produce the structure but the investment in trait growth differs between males and females (e.g., enlarged forelegs in harlequin beetles [Zeh and Zeh 1992] and eyestalks in Diopsid flies [Wilkinson 1993; Baker and Wilkinson 2001]). In contrast, the weapons of many beetles are produced by only one sex (most often males). The other sex does not produce them at all or has only vestigial/rudimentary versions of the structure (sexual dimorphism in the presence/absence of the structure).

This study focuses primarily on the evolution of sexual dimorphism in the presence/absence of horns. Species were scored as sexually dimorphic if only a single sex produced the horns (e.g., H3, purple horns, fig. 2A, 2B) and sexually monomorphic if both sexes produced the horn, even if the relative lengths of these horns differed between males and females (e.g., H1, blue, and H4, green horns, fig. 2; see also fig. 9D).

Complete loss of a horn also resulted in a form of sexual monomorphism (for lack of expression of the horn). However, because these forms of sexual monomorphism do not involve production of the horn by any individuals, we do not address them here; all references to sexual monomorphism refer to situations where both males and females produce a horn.

To avoid confounding scores of male and sexual di- 
Table 1: Scoring of male and sexual dimorphism for the presence/absence of horns

\begin{tabular}{|c|c|c|c|}
\hline & \multirow{2}{*}{$\begin{array}{l}\text { Horn } \\
\text { type }\end{array}$} & \multicolumn{2}{|c|}{ Dimorphism? } \\
\hline & & Male & Sexual \\
\hline Onthophagus acuminatus Harold & H1 & Yes & Yes \\
\hline O. aeruginosus Roth & $\mathrm{H} 1$ & Yes & Yes \\
\hline O. alcyonides d'Orbigny & $\mathrm{H} 1$ & Yes & Yes \\
\hline O. asperulus d'Orbigny & $\mathrm{H} 1$ & Yes & Yes \\
\hline O. australis Guerin & $\mathrm{H} 1$ & Yes & Yes \\
\hline O. binodis Thunberg & $\mathrm{H} 4$ & Yes & Yes \\
\hline O. capella Kirby & $\mathrm{H} 1$ & Yes & Yes \\
\hline O. cribripennis d'Orbigny & $\mathrm{H} 1$ & Yes & Yes \\
\hline O. crinitus panamensis Bates & $\mathrm{H} 1$ & Yes & Yes \\
\hline O. evanidus Harold & $\mathrm{H}^{\mathrm{a}}$ & No & No \\
\hline \multirow[t]{2}{*}{ O. ferox Harold } & H1 & No & No \\
\hline & $\mathrm{H} 4$ & No & No \\
\hline O. fuliginosus Erichson & $\mathrm{H} 1$ & Yes & Yes \\
\hline O. gazella Fabricius & $\mathrm{H} 1$ & Yes & Yes \\
\hline O. granulatus Boheman & $\mathrm{H} 4$ & No & No \\
\hline \multirow[t]{2}{*}{ O. haagi Harold } & $\mathrm{H} 1$ & Yes & No \\
\hline & $\mathrm{H} 4$ & No & No \\
\hline O. hecate Panzer & $\mathrm{H} 4$ & Yes & Yes \\
\hline O. incensus Say & $\mathrm{H} 1$ & Yes & Yes \\
\hline O. laminatus Macleay & $\mathrm{H} 4$ & No & No \\
\hline \multirow[t]{2}{*}{ O. lanista Macleay } & H1 & No & No \\
\hline & $\mathrm{H} 4$ & No & No \\
\hline O. marginicollis Harold & $\mathrm{H} 1$ & Yes & Yes \\
\hline \multirow[t]{2}{*}{ O. mjobergi Gillet } & $\mathrm{H}^{\mathrm{a}}$ & No & No \\
\hline & $\mathrm{H} 4$ & No & No \\
\hline \multirow[t]{2}{*}{ O. nigriventris d'Orbigny } & $\mathrm{H} 4(1)$ & Yes & Yes \\
\hline & $\mathrm{H} 4(2)$ & No & No \\
\hline O. nuchicornis Linnaeus & $\mathrm{H} 1$ & Yes & Yes \\
\hline \multirow[t]{3}{*}{ O. pentacanthus Harold } & H1 & No & No \\
\hline & $\mathrm{H} 4$ & No & No \\
\hline & H5 & No & No \\
\hline \multirow[t]{3}{*}{ O. praecellens Bates } & $\mathrm{H} 1^{\mathrm{a}}$ & No & No \\
\hline & $\mathrm{H} 3$ & Yes & Yes \\
\hline & $\mathrm{H} 4$ & No & No \\
\hline \multirow[t]{2}{*}{ O. sagittarius Fabricius } & $\mathrm{H} 2$ & No & No \\
\hline & $\mathrm{H} 4$ & No & No \\
\hline O. sharpi Harold & $\mathrm{H} 3$ & Yes & Yes \\
\hline \multirow[t]{2}{*}{ O. sloanei Blackburn } & $\mathrm{H} 1$ & Yes & Yes \\
\hline & $\mathrm{H} 4$ & No & No \\
\hline O. sugillatus Klug ${ }^{\mathrm{b}}$ & $\mathrm{H} 1$ & Yes & Yes \\
\hline O. taurus Schreber & H1 & Yes & Yes \\
\hline O. vermiculatus Frey & H1 & Yes & Yes \\
\hline
\end{tabular}

Note: Horns develop from one of five locations: the base (H1), center $(\mathrm{H} 2)$, or front $(\mathrm{H} 3)$ of the head or the center $(\mathrm{H} 4)$ or sides (H5) of the thorax.

a Tiny/rudimentary versions of the horn; these were not scored as horns by Emlen et al. (2005).

b Determined to be "near to" the named taxon.

morphism, horns in females were compared with horns of large males. Otherwise, male-dimorphic taxa would al- ways also be sexually dimorphic: if one male size class had horns and the other did not, then females would necessarily differ from one or the other male form. By defining sexual dimorphism as differential horn production between females and large males, all combinations of dimorphism are possible (e.g., sexual dimorphism without male dimorphism would occur when all males produce a horn that is absent from females, and male dimorphism without sexual dimorphism would occur when small males dispense with production of a horn that is present in both large males and females). We scored males and females of each species for the presence or absence of horns at each of the five developmental locations (H1-H5). In all cases, determinations of horn presence were made from direct observations of specimens.

\section{Mapping Characters onto the Phylogeny}

The phylogeny used in this study is from Emlen et al. (2005) and is based on DNA sequences from regions of four nuclear (28s, HRMT1L4, ARD1, NF1) and three mitochondrial (16s, CO1, CO2) genes (3,315 base pairs total, 837 parsimony informative) from 48 Onthophagus species and three outgroups. Tree construction used maximum likelihood analyses and resulted in a single most likely tree with a score of $-\ln 25,561.3$ (see Emlen et al. 2005 for methods and justification). Eighty-nine percent of the nodes in this tree were supported by maximum likelihood or parsimony bootstrap values $>50$ (100 and 10,000 pseudoreplicates, respectively) or by Bayesian posterior probabilities of clade occurrence $>80$ (Emlen et al. 2005).

Because sufficient DNA could be extracted from only a single individual, large population samples of each species were not necessary for inclusion in the original phylogeny. Twenty of the 51 taxa included in Emlen et al.'s (2005) study were represented by only one or a few individuals (inadequate samples for estimating the presence or absence of dimorphism in weapon expression), and these taxa were dropped from the phylogeny for this study.

The Backdrop: Evolution of Horns. The evolutionary radiation in Onthophagus horn morphologies forms the backdrop for our study of dimorphism in the expression of horns. The five horn locations (H1-H5) reflect developmentally distinct and evolutionarily independent structures (i.e., they are not mutually exclusive alternative states for a single horn character; Emlen et al. 2005), and it is possible for Onthophagus taxa to have all combinations of these structures. For this reason, we reconstruct the evolution of dimorphic patterns of expression separately for each horn type ( $\mathrm{H} 1$, blue, fig. 5; $\mathrm{H} 2$, red, and $\mathrm{H} 3$, purple, fig. 6; $\mathrm{H} 4$, green, and $\mathrm{H} 5$, orange, fig. 7). 


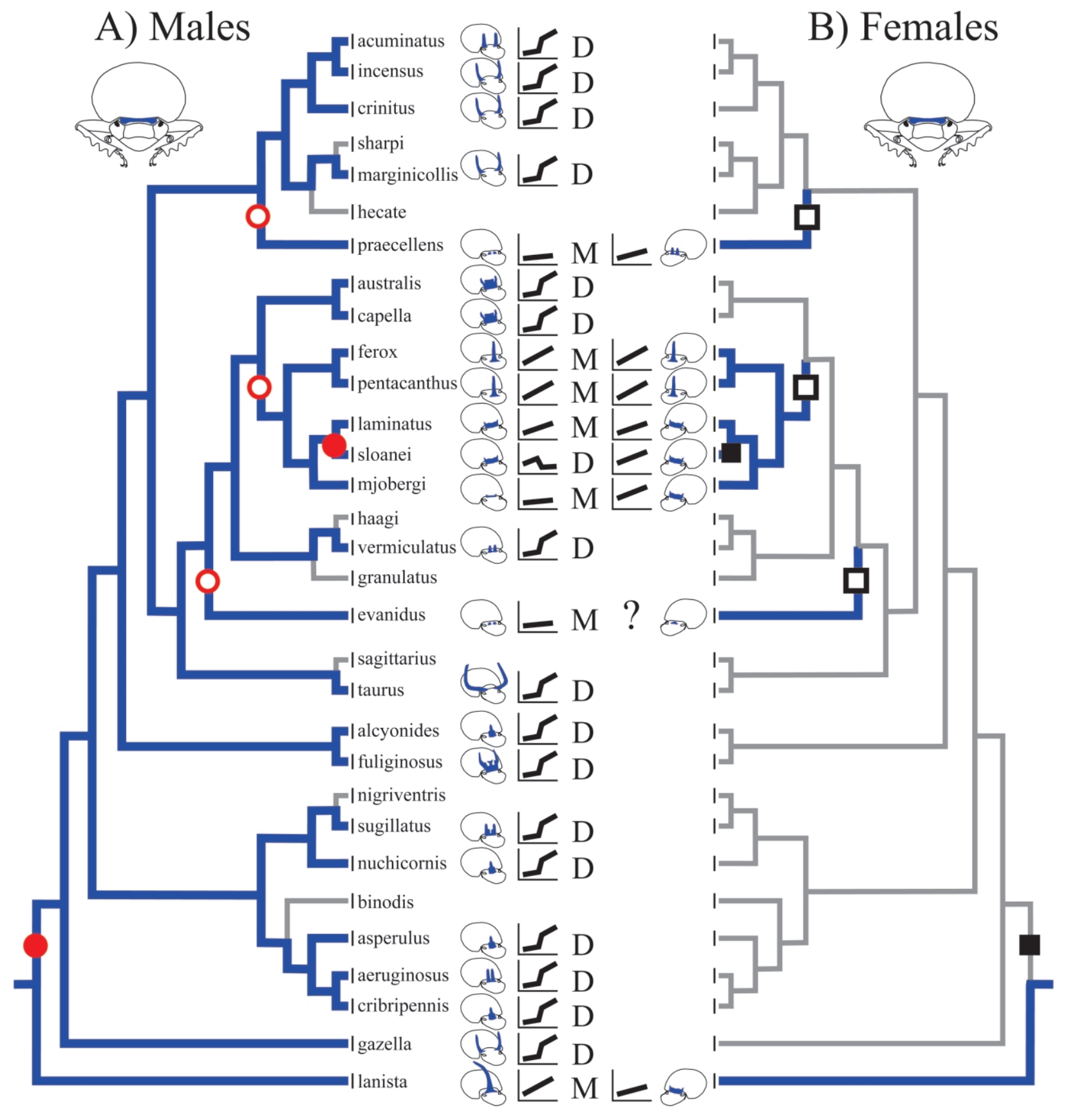

Figure 5: Evolution of male and sexual dimorphism in the expression of horns at the base of the head (H1, blue). Branches reconstruct the evolution of this horn type (thick blue lines, horn present; thin gray lines, horn absent) in males $(A)$ and females $(B)$. For each species producing this horn, the shape of the male horn length/body size scaling relationship is indicated (broken = male dimorphic; linear $=$ male monomorphic), as is the occurrence of sexual dimorphism $(D)$ or sexual monomorphism $(M)$ for presence/absence of the horn. Reconstructions of the evolution of male dimorphism are shown on the left and of sexual dimorphism on the right. Horns at the base of the head appear to be ancestral to the genus (see also Emlen et al. 2005), and these horns are not likely to have exhibited either male or sexual dimorphism. Once gained, male dimorphism was subsequently lost three times (open red circles) and regained a single time (solid red circle). Once gained, sexual dimorphism also was subsequently lost three times (open black squares) and regained once (solid black square). Pictures illustrate head horns (H1) only (other horn types removed for clarity). Tree topology from Emlen et al. (2005). 


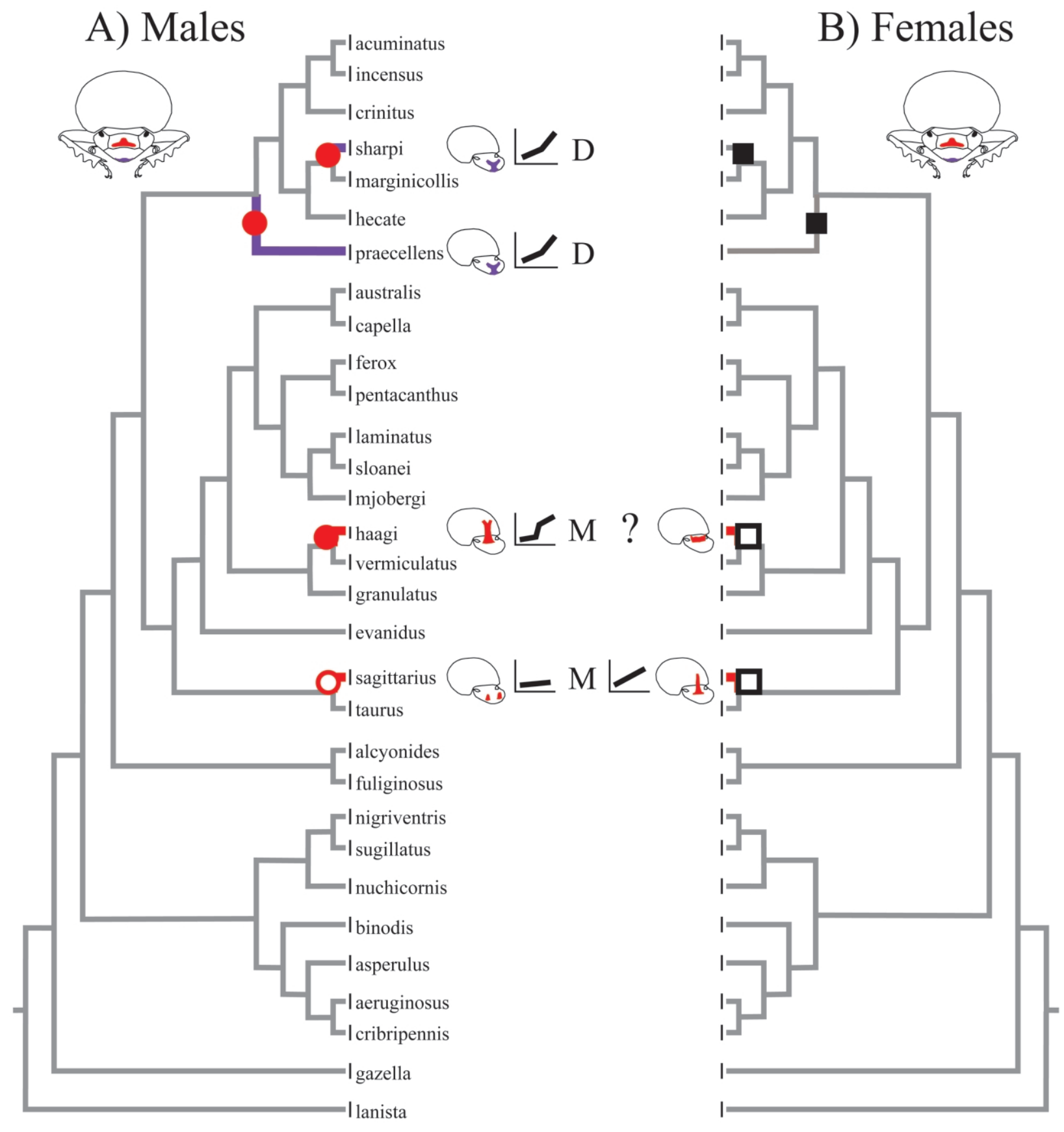

Figure 6: Evolution of male and sexual dimorphism in the expression of horns at the center (H2, red) and front (H3, purple) of the head. Branches reconstruct the evolution of these horn types (thick red or purple lines, horn present; thin gray lines, horn absent) in males $(A)$ and females $(B)$. For each species producing these horns, the shape of the male horn length/body size scaling relationship is shown, as is the occurrence of sexual dimorphism $(D)$ or sexual monomorphism $(M)$ for presence/absence of the horn. These horns were gained four times in males; of these, three are presently male dimorphic (solid red circles), and one is male monomorphic (open red circle). Two of these horns exhibited sexual dimorphism (solid black squares), and two were sexually monomorphic (i.e., expressed in females as well as males; open black squares). Pictures illustrate head horns (H2, H3) only (other horn types not shown). 


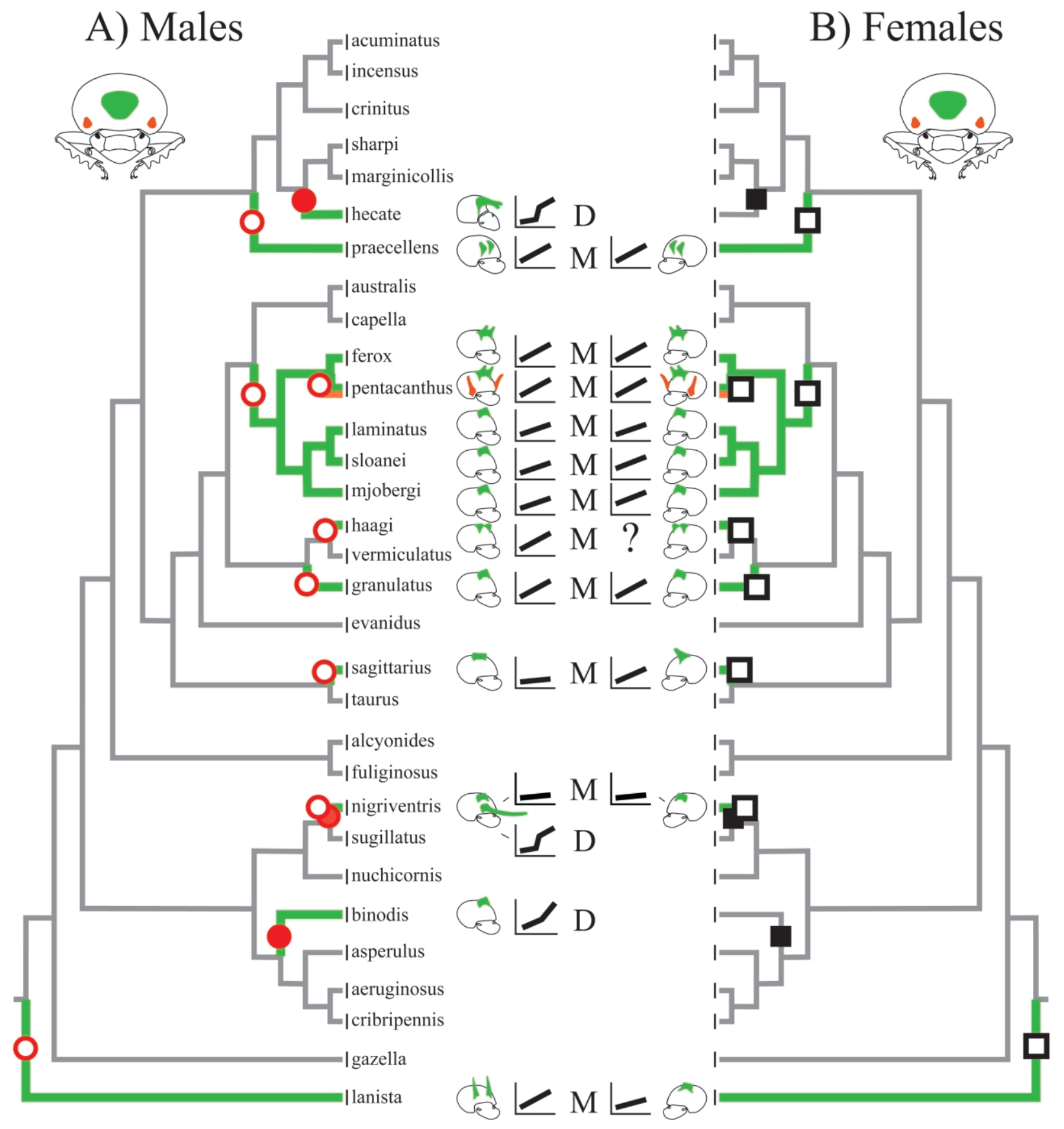

Figure 7: Evolution of male and sexual dimorphism in the expression of horns at the center (H4, green) and sides (H5, orange) of the thorax. Branches reconstruct the evolution of these horn types (thick green or orange lines, horn present; thin gray lines, horn absent) in males $(A)$ and females $(B)$. Male and sexual dimorphism are indicated as in figures 5, 6. Thoracic horns were gained 11 times in males; of these, three were male dimorphic (solid red circles), and eight were male monomorphic (open red circles). Three of these horns were sexually dimorphic (solid black squares), and eight were sexually monomorphic (open black squares). Pictures illustrate thorax horns (H4, H5) only (other horn types not shown). 
Figures 5-7 illustrate gains and losses of horns as reconstructed from analyses of the full sample of 51 taxa included in Emlen et al.'s (2005) study and are taken from those original analyses. ${ }^{2}$ For those analyses, each horn type (H1-H5) was mapped on the phylogeny as a two-state character using parsimony and MacClade 4.0 (Maddison and Maddison 1999). Horns in females were mapped as separate characters from horns in males. Mapping female horns separately permitted us to explore whether gains of horns in females occurred independently from gains of horns in males and whether these same events were associated with gains or losses of male and sexual dimorphism. Thus, the five horn locations were mapped separately for males and females, for a total of 10 horn types.

Evolution of Male and Sexual Dimorphism. Each type of dimorphism was mapped on the phylogeny as a separate two-state character using parsimony and MacClade 4.0 (gains and losses given equal probabilities; Maddison and Maddison 1999). Horn dimorphism was mapped separately for each horn type and separately for males and females.

To test for correlated evolutionary changes among mapped discrete characters, we used the concentrated changes test (Maddison 1990) as implemented in MacClade 4.0 (Maddison and Maddison 1999). Specifically, because a prior study suggested that taxa with male dimorphism were also likely to be sexually dimorphic (Emlen and Nijhout 2000), we explored whether changes in male dimorphism were likely to occur on the same branches as changes in sexual dimorphism.

Rooting the Tree. Horns are a derived condition within the Coleoptera and appear to have arisen multiple times within the superfamily Scarabaeoidea (Darwin 1871; Arrow 1951). Head and pronotal outgrowths similar to those described here occur in many species of the rhinoceros and Hercules beetles (Dynastinae) and in the Goliath beetles (Cetoniinae), as well as in many dung beetles of the subfamily Scarabaeinae.

The beetle lineages included in our phylogeny are all within the tribe Onthophagini (subfamily Scarabaeinae), and recent phylogenetic treatments of this subfamily suggest that the closest sister clades to the Onthophagini are the tribes Oniticellini and Onitini (Villalba et al. 2002; Philips et al. 2004), each of which contains species with

\footnotetext{
2 The very small head horns ( $\mathrm{H} 1$, blue) of O. evanidus, O. mjobergi, and O. praecellens were scored as absent by Emlen et al. (2005), who focused on the evolution of enlarged weapons. In this study we focus more broadly on the evolution of horns, including evolutionary reductions in horn expression and rudimentary horns, and so we score these highly reduced horns as present.
}

horns. Importantly, horns in these sister tribes are not dimorphic (see our definitions above); horns are produced by males of all sizes, as well as females (e.g., Euoniticellus intermedius [Oniticellini]: Lailvaux et al. 2005; Bubas bison [Onitini]: Hunt and Simmons 1998). Immediately basal to the Onthophagini, Oniticellini, and Onitini are the tribes Eurysternini and Sisyphini (Philips et al. 2004), neither of which contain species with horns.

Consequently, present hypotheses for the history of this subfamily suggest that Onthophagine horns arose in the common ancestor of the tribes Onthophagini, Oniticellini, and Onitini. Furthermore, both the sister tribes to the Onthophagini, and the most basal lineage included in our phylogeny (O. lanista), show no evidence of either sexual or male dimorphism in horn expression, suggesting that horns arose in these beetles as a structure expressed by all individuals - that is, that horn production, once gained, was the default developmental pathway. Sexual and male dimorphism in the expression of horns would then have evolved as derived conditions, possibly through gains of ecdysteroid pulses at the end of the larval feeding period that suppressed growth of the horns. This sequence of events agrees with our phylogeny, with other recent phylogenetic treatments of the subfamily (Villalba et al. 2002; Philips et al. 2004), and with the recognized function of small feeding period pulses of ecdysteroid (all of which appear to reprogram gene expression away from an existing pattern [e.g., Andres et al. 1993; Nijhout 1994, 1999a, 1999b; Riddiford 1994, 1996; Gilbert et al. 1996]). For these reasons, we use this reconstruction to root our phylogeny in the figures and tables. Specifically, we assume that the immediate ancestor of this clade had a horn at the base of the head (H1) that exhibited neither male nor sexual dimorphism.

However, reconstructing ancestor states is problematic under the best of circumstances (e.g., Cunningham et al. 1998; Losos 1999), and it is especially risky here because of the relatively small proportion of included taxa ( $1 \%$ of the genus) and because of the fact that the initial gain of horns in these beetles preceded the origin of the genus (and therefore the period covered by our phylogeny). Consequently, we also consider three alternative ancestor state reconstructions (sexually dimorphic but not male dimorphic, male dimorphic but not sexually dimorphic, and both sexually and male dimorphic). Importantly, although these alternatives affect the starting conditions for the period covered by this phylogeny, and the default state of the endocrine mechanism described above, they do not affect the qualitative result of multiple transformations in sexual and male dimorphism, nor do they alter the pattern of correlated evolution of sexual and male dimorphism. 


\section{Results}

\section{Evolution of Male Dimorphism in Horn Expression}

Most extant Onthophagus taxa have horns at the base of the head of males ( $\mathrm{H} 1$, blue). This horn type is reconstructed as ancestral (Emlen et al. 2005; fig. 5); 24 of the taxa included in this study had male horns at the base of the head (thick blue branches, fig. 5A). The ancestor of this clade is predicted to have been male monomorphic (see "Methods"), but 17 of the 24 taxa with this horn type are at present male dimorphic.

Once gained, male dimorphism in the expression of this horn was lost three times (open red circles, fig. 5A) and regained once (solid red circle, fig. 5A). Losses of male dimorphism resulted from populations becoming fixed for either the horned or the hornless male morphology. Fixation for the horned male form (all males of all sizes produce the horn) occurred once (lineage leading to the Onthophagus ferox, O. pentacanthus, O. laminatus, $O$. sloanei, and O. mjobergi clade; fig. 5A). Fixation for the hornless male form (all males of all sizes produce only rudimentary horns) occurred two times (lineages leading to $O$. praecellens and O. evanidus; fig. $5 A$ ). In both situations, populations had linear scaling relationships between horn length and body size and unimodal frequency distributions of male horn lengths (e.g., fig. 1C).

Once lost, male dimorphism was subsequently regained in the lineage leading to O. sloanei. This event is remarkable in that the polarity of the developmental threshold, once regained, was reversed. In this species, males smaller than a threshold body size produce a head horn ( $\mathrm{H} 1$, blue) not present in large males (fig. 9C).

Novel male horn types ( $\mathrm{H} 2-\mathrm{H} 5)$ were gained 15 separate times in the period covered by this phylogeny (thick red, purple, green, or orange branches, figs. $6 A, 7 A$ ). Six of these new horn types exhibited male-dimorphic expression (large males produce the horn, but small males do not; solid red circles, figs. $6 A, 7 A$ ); nine were male monomorphic (all males of all sizes produced the horn; open red circles, figs. $6 A, 7 A$ ). Figure 7 suggests that thoracic horns (H4, green) also were ancestral to this genus. However, full analysis with the 48 species included by Emlen et al. (2005) suggests that the ancestor to Onthophagus had head ( $\mathrm{H} 1$, blue) horns only, and for this reason, we reconstruct the thoracic (H4, green) horn of O. lanista as a gain of a novel horn type.

The ancestral horn type ( $\mathrm{H} 1$, blue) was replaced by one of these novel horns eight separate times; that is, a new horn type became the predominant weapon, either eclipsing or completely replacing the ancestral horn type. In six of these instances, the novel horn was male dimorphic. Thus, in these cases, alternative (horned vs. hornless) male morphologies were maintained despite major evolutionary transformations in horn morphology. In two instances, novel horn types replaced the ancestral horn type without retaining male-dimorphic expression, resulting in a loss of body size-dependent alternative male morphologies ( $O$. sagittarius, O. granulatus; fig. 7A).

Novel horns were added to the ancestral horn type seven times; that is, they were added as complements to an existing larger horn. In all seven cases, these secondary horns were male monomorphic, resulting in several species that were male dimorphic for the primary horn type and male monomorphic for secondary horn types (e.g., O. haagi, O. nigriventris, O. praecellens, O. sloanei).

Combined, these results show evolutionary lability of this developmental threshold mechanism, with multiple losses of dimorphic horn expression (through fixation at either of the alternative male morphologies), with novel horn types apparently replacing the ancestral horn type as downstream targets of the threshold mechanism, and with a reversal of the polarity of the threshold, so that the link between horn expression and circumstance (e.g., growth conditions, body size) was reversed.

\section{Evolution of Sexual Dimorphism in Horn Expression}

The ancestor of this genus was likely to have been sexually monomorphic as well as male monomorphic in its expression of the ancestral horn ( $\mathrm{H} 1$, blue; see "Methods"), but 17 of the 24 species with this horn type at present exhibit sexual dimorphism-no females produce the horn (table 1; fig. 5).

Once gained, sexual dimorphism in the expression of this horn type was lost three times (open black squares, fig. $5 B$ ) in lineages in which females began producing the horn (thick blue branches, fig. 5B). Sexual dimorphism was subsequently regained one time (solid black square, fig. $5 B$ ). However, this regain of sexual dimorphism did not involve a secondary loss of this horn in females. Instead, females retained the horn, but large males did not. This species (O. sloanei) was the same species characterized by a reversed-polarity male dimorphism: small males and females produce a head horn ( $\mathrm{H} 1$, blue) no longer expressed by large males (fig. 9C).

Of the 15 gains of novel male horn types ( $\mathrm{H} 2-\mathrm{H} 5$; thick red, purple, green, or orange branches, figs. $6 A, 7 A$ ), five were sexually dimorphic; that is, they were not expressed in females (solid black squares, figs. $6 B, 7 B$ ). Ten of the novel horn types were sexually monomorphic (i.e., they were expressed to some extent in females as well as males; open black squares, figs. $6 B, 7 B$ ). Interestingly, in one of these species, female horns are now qualitatively different from the corresponding male horn (O. sagittarius; red horns, figs. $2 \mathrm{C}, 6 \mathrm{~B})$. Although both sexes produce horns at the center of the head (the frons; H2, red), the shape 
and precise location of these horns differ. Females produce a single long horn in the center of the frons, whereas males produce a pair of shorter horns at the sides of the frons.

Male dimorphism and sexual dimorphism did not evolve independently (fig. 8). Gains and losses of male dimorphism in the ancestral horn type (H1, blue) corresponded to gains and losses of sexual dimorphism in the expression of this same horn (concentrated changes test: 2/2 gains, $P<.000 ; 3 / 3$ losses, $P<.006$; table 2 ).

Similarly, all nine gains of novel male-monomorphic horns (i.e., lacking male dimorphism) lacked sexual dimorphism as well; that is, these horns were expressed in both females and males (concentrated changes test: 9/9 gains, $P<.000)$. Of the six gains of novel male-dimorphic horn types, five were also sexually dimorphic (concentrated changes test: $5 / 6$ gains, $P<.000$ ). Only one horn in one species failed to fit this pattern. In $O$. haagi, a male horn $(\mathrm{H} 2$, red) was male dimorphic but also was expressed in females (fig. 6).

Combined, these results indicate a remarkable correspondence of evolutionary events: gains and losses of male and sexual dimorphism coincided for 19 of the 20 observed changes in patterns of horn expression (fig. 8; table 2). Stated another way, if horns were present in females, they were also present in small males; if horns were absent in females, they were also absent in small males. This pattern holds even within species. A number of species produce multiple horns, and these different horn types can display different patterns of expression. For example, in O. praecellens, the male horn at the front of the head (H3, purple) is male dimorphic (not present in small males), whereas horns at the base of the head ( $\mathrm{H1}$, blue) and on the thorax $(\mathrm{H} 4$, green) are male monomorphic (they are present in small males; table 1). These within-species, among-horn differences coincide exactly with among-horn differences in sexual dimorphism: the horn at the front of the head (H3, purple) is sexually dimorphic (not present in females), whereas the other horn types ( $\mathrm{H} 1$, blue; $\mathrm{H} 4$, green) are not (they are present in females; table 1; fig. $2 B$ ).

Alternative reconstructions of the ancestor of this clade did not alter the qualitative result of multiple transformations in patterns of horn dimorphism, nor did they affect the correlated evolution observed between forms of dimorphism. Assuming that the ancestor had head ( $\mathrm{H} 1$, blue) horns that were male dimorphic but not sexually dimorphic or that the ancestor horns were sexually dimorphic but not male dimorphic, each resulted in 21 transformations in presence/absence of dimorphism, with 17 of these events involving concerted changes in both male and sexual dimorphism. Assuming that the ancestor had head ( $\mathrm{H} 1$, blue) horns that were both male and sexually dimorphic resulted in 19 of 21 transformations coinciding between male and sexual dimorphism.

\section{Discussion \\ Evolution of Developmental Thresholds: Lability}

It has long been recognized that organisms are constructed from a hierarchical series of relatively dissociable developmental subunits, or modules (Needham 1933; reviewed in Cheverud 1996; Raff 1996; Wagner 1996; Von Dassow and Munro 1999; Bolker 2000; Raff and Sly 2000; WestEberhard 2003; Schlosser and Wagner 2004). Modules have been described as "fundamental units" of development (Atchley and Hall 1991) and are generally recognized as having high genetic and physiological integration within the module but relatively weak genetic correlation/integration between modules (for recent reviews, see Cheverud 1996; Raff 1996; Wagner 1996; Raff and Sly 2000; WestEberhard 2003). This results in both developmental and functional dissociability and the potential for alternative modules to evolve along relatively independent trajectories (West-Eberhard 2003). Modularity itself has been considered to be an adaptive/evolved characteristic of organisms (e.g., Wagner and Altenberg 1996; Williams and Nagy 2001), and it is predicted to have profound consequences for the directions and speed of morphological and behavioral evolution, leading to rapid transformations of complex phenotypes, recurrent evolutionary reversals between phenotypic alternatives, the origin of novel phenotypes, and the evolution of organismal complexity in general (Alberch 1982; Cheverud 1984; Bonner 1988; Raff 1996; Wagner 1996; Kirschner and Gerhart 1998; Raff and Sly 2000; West-Eberhard 2003; Schlosser and Wagner 2004).

Many aspects of development have been described as modular, ranging from genetic and physiological processes (e.g., the patterning network responsible for defining segment polarity in insects; Von Dassow et al. 2000) to limb primordia (Jockusch et al. 2000; Williams and Nagy 2001), sequential metamorphic developmental stages (e.g., larval and adult forms; Nijhout 1999b), and facultatively expressed alternative phenotypes (i.e., polyphenisms; WestEberhard 1992, 2003; Raff 1996; Nijhout 1999a).

Insect polyphenisms may comprise some of the most conspicuous and intuitive examples of developmental modularity (West-Eberhard 1989, 1992, 2003; Brakefield et al. 1996; Raff 1996; Nijhout 1999a; Abouheif and Wray 2002). Polyphenisms generally result from a threshold mechanism that couples expression of phenotypic alternatives with external circumstances encountered by animals as they develop (e.g., Nijhout and Wheeler 1982; Hardie and Lees 1985; Zera and Denno 1997; Nijhout 1999a; Dingle 2002; Hartfelder and Emlen 2004). These thresholds typically coordinate the expression of suites of morphological, physiological, and behavioral traits and can generate extreme differences between the developmental alternatives (e.g., stem and catkin mimicking forms of ge- 
A) Male Dimorphism

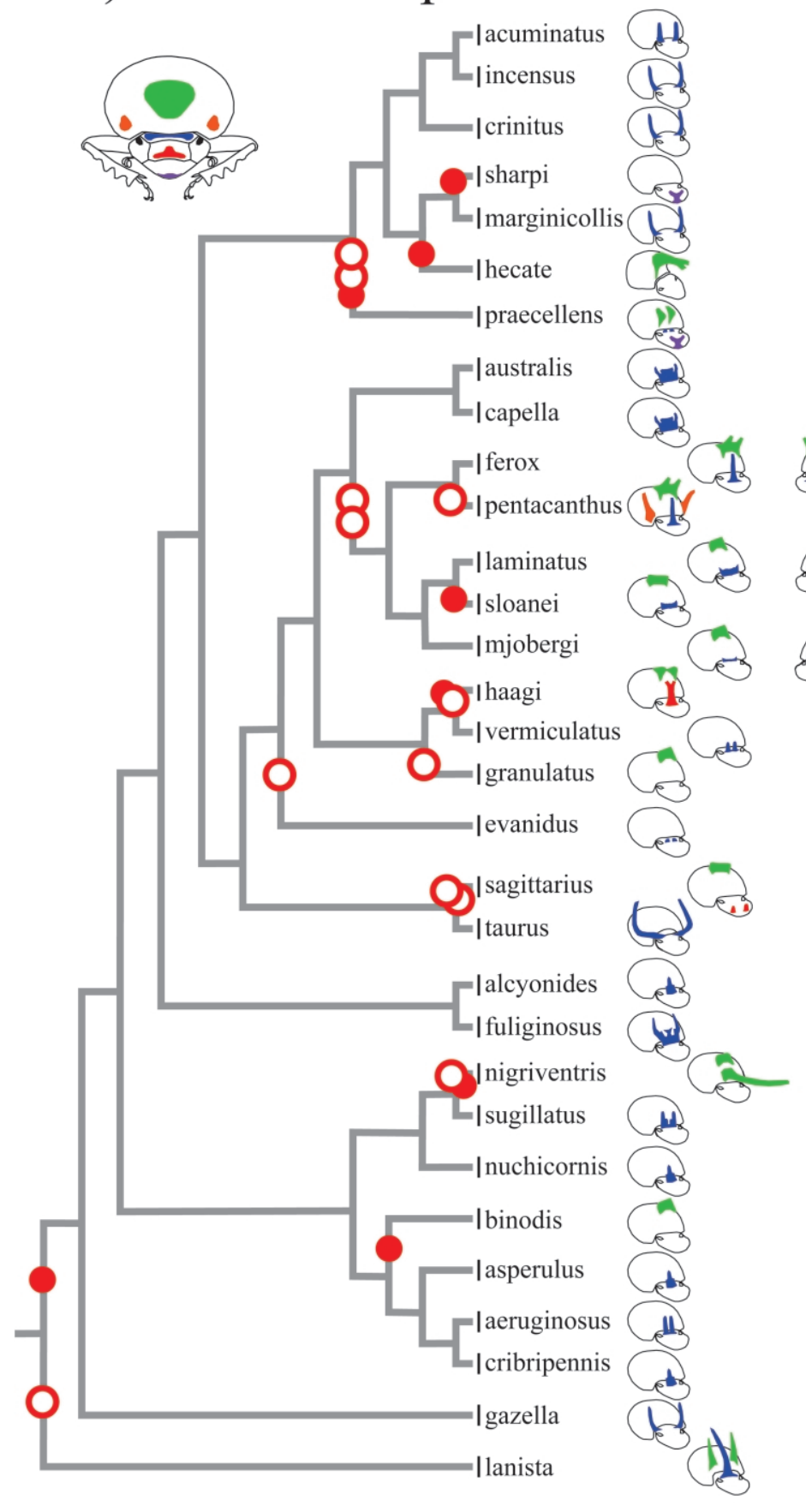

B) Sexual Dimorphism

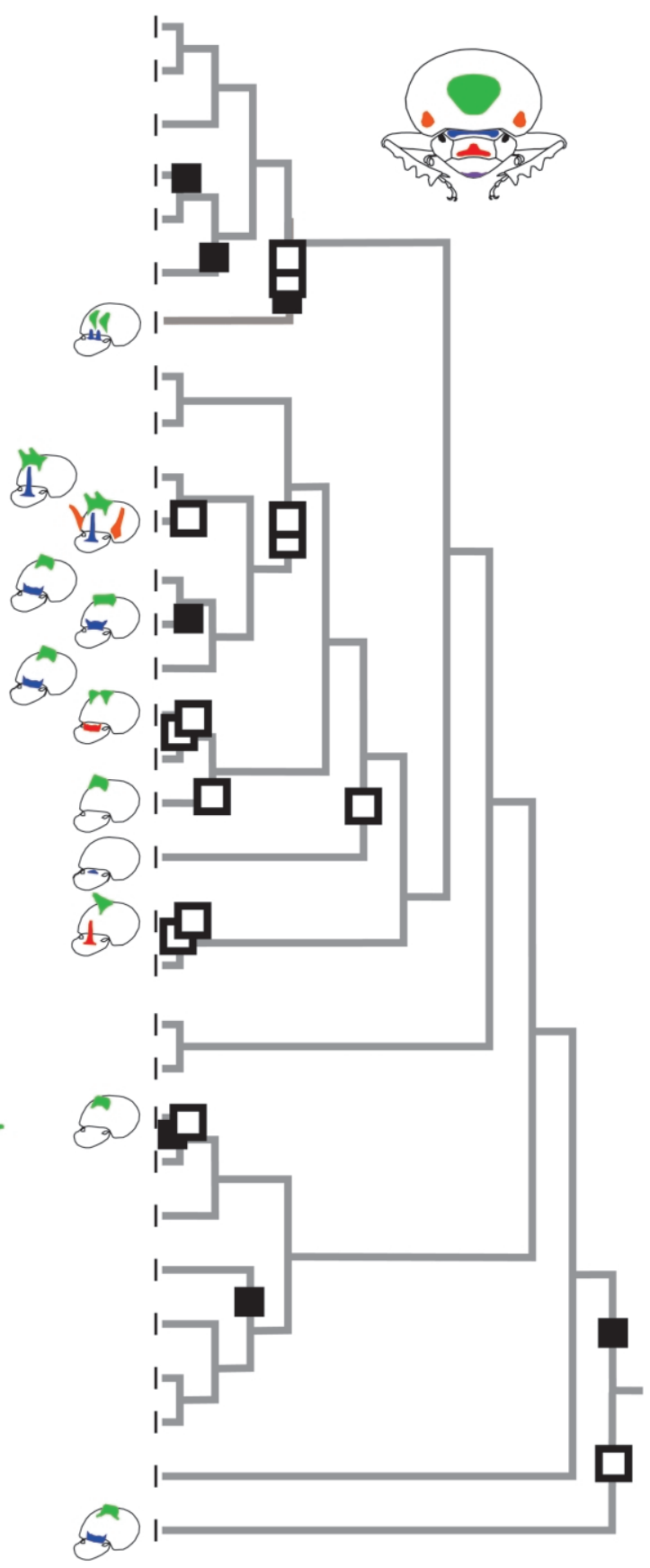

Figure 8: Correlated evolution of male and sexual dimorphism in the expression of beetle horns. Losses of male dimorphism in the expression of the ancestral horn type (H1) and gains of novel horn types (H2-H5) that were male monomorphic are shown by open red circles. Gains of male dimorphism (H1) and gains of novel horns (H2-H5) that were male dimorphic are shown by solid red circles. Similarly, losses of sexual dimorphism in the ancestral horn type and gains of novel horns that were sexually monomorphic are shown by open black squares. Gains of sexual dimorphism and gains of novel horns that were sexually dimorphic are indicated by solid black squares. In 19/20 instances, changes in sexual dimorphism coincided with corresponding changes in male dimorphism (table 2). 
Table 2: Correlated evolution of male and sexual dimorphism

\begin{tabular}{|c|c|c|c|c|}
\hline Horn type & $\begin{array}{c}\text { Male } \\
\text { dimorphism }\end{array}$ & $\begin{array}{c}\text { Sexual } \\
\text { dimorphism }\end{array}$ & $\begin{array}{c}\text { No. } \\
\text { coinciding }\end{array}$ & $P$ \\
\hline \multicolumn{5}{|l|}{ H1 (ancestral horn type): } \\
\hline Gains of dimorphism & 2 & 2 & $2 / 2$ & .000 \\
\hline Losses of dimorphism & 3 & 3 & $3 / 3$ & .006 \\
\hline \multicolumn{5}{|l|}{ H2, H3 (novel head horns): } \\
\hline Gains with dimorphism & 3 & 2 & $2 / 3$ & .006 \\
\hline Gains without dimorphism & 1 & 2 & $1 / 2$ & $.074 \mathrm{NS}$ \\
\hline \multicolumn{5}{|l|}{ H4, H5 (novel thorax horns): } \\
\hline Gains with dimorphism & 3 & 3 & $3 / 3$ & .000 \\
\hline Gains without dimorphism & 8 & 8 & $8 / 8$ & .000 \\
\hline Total gains of dimorphism & 8 & 7 & $7 / 8$ & .000 \\
\hline Total losses of dimorphism & 12 & 13 & $12 / 13$ & .000 \\
\hline
\end{tabular}

Note: Presence/absence of dimorphism was scored for each horn type (H1-H5) and species and was mapped on the phylogeny as two-state characters (monomorphic, dimorphic). Concentrated changes tests were performed to determine whether gains (or losses) of sexual dimorphism were concentrated on branches of the tree associated with gains (or losses) of male dimorphism (and vice versa) using MacClade 4.0. Bonferroni correction for $P$ values $(\alpha=0.05)=0.006$. NS $=$ not significant.

ometrid caterpillars [Greene 1989]; reproductive and soldier castes in ants [Wilson 1971; Wheeler 1991], termites [Lüscher 1960; Noirot and Pasteels 1987; Miura 2001], and aphids [Stern and Foster 1996; Stern et al. 1996]; and fighting and dispersing male bees [Kukuk and Schwarz 1988; Danforth 1991]).

In all of these examples, both the threshold mechanism itself and the downstream phenotypic alternatives regulated by the threshold are predicted to act as relatively independent modules (West-Eberhard 1992, 2003). Thus, selection should be able to affect the regulation of trait expression without affecting the form of the traits themselves, and vice versa (disassociation of threshold and phenotype; Raff and Kaufman 1983; West-Eberhard 1992, 2003; Roff 1996). For example, swallowtail butterfly caterpillars molt into either a green or brown pupa depending on the substrate they encounter at the time of pupation (Hazel 1995). A recent comparative study of the endocrine mechanisms regulating pupal color polyphenism demonstrated that both the peacock butterfly (Inachis io) and the black swallowtail butterfly (Papilio polyxenes) utilize the same signal hormone (pupal melanization-reducing factor [PMRF]) but that the effects of this hormone are reversed: high levels of PMRF trigger a switch from brown to green pupal color in $I$. io and a switch from green to brown pupal color in P. polyxenes (Starnecker and Hazel 1999). Thus, the regulatory mechanism has changed, but the downstream phenotypes (pupal colors) have not (West-Eberhard 2003).

Threshold mechanisms are also predicted to facilitate independent (even divergent) evolution between the downstream phenotypes so that changes in one of the forms may arise with little or no effects on the alternative form (reviewed in West-Eberhard 1992, 2003; Emlen and Nijhout 2000). Finally, threshold mechanisms are predicted to lead to apparent evolutionary reversals and/or recurrences, as populations become fixed for one or the other morph (West-Eberhard 1989, 1992, 2003). Beetle horns, and in particular male and sexual dimorphism in the expression of horns, provide empirical support for all of these predictions.

Several recent studies have demonstrated that the threshold body size associated with male horn expression can evolve rapidly (Kawano 1995a, 1995b; Emlen 1996; Moczek et al. 2002; Moczek and Nijhout 2003; Rowland 2003), and major shifts in this developmental threshold appear to have occurred with little impact on the morphologies of the alternative forms themselves. That is, genetic changes in the threshold mechanism (e.g., the critical body size) did not alter the downstream phenotypes (e.g., the horns) regulated by this mechanism.

Here, we demonstrate that the reverse scenario may also be important. We show that downstream phenotypes can evolve without apparent changes to the regulatory mechanism (e.g., the threshold). Six separate times, the physical location of male horns changed dramatically without apparent changes to the threshold (branches leading to $\mathrm{On}$ thophagus sharpi, O. praecellens, O. hecate, O. haagi, O. nigriventris, and $O$. binodis). This suggests that in these beetle lineages, novel traits were subsumed within an ancestral regulatory (threshold) mechanism, maintaining a body size-dependent dimorphism in horn expression despite changes in the physical location of the developing horn.

Beetle horn evolution supports the second prediction as well: major evolutionary transformations in the shape 
(horn morphology) and/or the relative size (horn scaling/ allometry) of horns of large males have occurred with little or no corresponding changes to the morphology of minor males or females (Kawano 1995a, 1995b; Emlen and Nijhout 2000; Rowland 2003; West-Eberhard 2003; Emlen et al. 2005), and changes to the relative sizes of horns in small males have occurred without affecting the expression of horns in large males (Kawano 1995a). Thus, the threshold mechanisms generating both male and sexual dimorphism appear to have facilitated relatively independent trajectories of evolution of large males, small males, and females.

Finally, we provide clear evidence that populations can lose dimorphism. Male dimorphism in horn expression was lost at least three times, resulting in populations fixed for the horned (one event) as well as for the hornless (two events) downstream male phenotype. Sexual dimorphism in horn expression was lost at least 13 times, resulting in both sexes producing the horn.

The most remarkable evidence of modularity of horn development occurred in the Australian species O. sloanei. In this beetle lineage, the ancestral situation of maledimorphic horn expression appears to have been first lost and then subsequently regained, but the polarity of the threshold, once regained, was reversed. In this species, and to our knowledge in this species only, small males produce a horn (H1, blue) not expressed in large males (fig. 9C). Although the morphology of the horn does not differ noticeably from its sister taxa (O. laminatus), the conditions under which this horn is expressed have changed dramatically. In O. laminatus, all males of all sizes develop the horn, whereas in O. sloanei only the smallest males do. Unfortunately, almost nothing is known about the behavior of this species (Matthews 1972), and the significance (if any) of this reversed pattern of horn expression remains unclear.

In summary, our comparative studies of the evolution of two threshold mechanisms reveal an extraordinary capacity for change (i.e., evolutionary lability), with multiple transformations in downstream phenotypes, multiple losses of facultative horn expression, and a complete reversal of the polarity of a developmental threshold.

\section{Evolution of Developmental Thresholds: Constraint}

Horn production by small males and females coincided more frequently than expected by chance. Whenever females produced a horn, small males also produced the horn, and vice versa (41/42 horns in this study). This pattern was evident from correlated changes in the presence/absence of each form of dimorphism (gains and losses of male and sexual dimorphism coincided for 19 of 20 events). It was also evident from the conspicuous ab- sence of two of the four possible combinations of male and sexual dimorphism: despite at least 20 separate gains and losses each of male and sexual dimorphism, no $\mathrm{On}^{-}$ thophagus horn exhibited sexual dimorphism without also being male dimorphic, and only one horn $(\mathrm{H} 2$, red, in $\mathrm{O}$. haagi) exhibited male dimorphism without also being sexually dimorphic (fig. 10). Clearly, these two forms of dimorphism have not evolved independently. Why not?

One possibility is that beetle populations have experienced a history of common selection on these two classes of individuals so that whenever selection favored female horns, it also favored small males with horns. However, such a consistent pattern of shared selection would appear unlikely for two reasons. First, species included in this study evolved under a tremendous diversity of social and physical situations, providing ample opportunities for selection on females and small males to diverge (e.g., population densities ranging from sparse to abundant, habitats ranging from tropical wet forests to grasslands and desert, and food sources ranging from dispersed and highly ephemeral to uniformly and consistently abundant). Second, females and small males use their horns in different contexts.

Females of all studied Onthophagus species dig tunnels into the soil beneath dung and pull dung into these tunnels to provision eggs (O. acuminatus [Emlen 1994, 1997a], O. taurus [Moczek and Emlen 2000; Hunt and Simmons 2002; Hunt et al. 2002], O. gazella, O. hecate, O. nigriventris, O. nuchicornis, O. sagittarius [J. Marangelo, D. Emlen, and L. Simmons, unpublished data]). Females occasionally fight with other females over tunnel ownership, and horns (if present) may aid females in these contests. However, horns are expensive to produce (Hunt and Simmons 1997; Emlen 2000, 2001), and Fitzpatrick et al. (1995) argue that fecundity costs of secondary sexual traits may represent a significant barrier to their evolution in females. As a result, horn expression may be cost effective for females only when levels of female-female aggression are high (e.g., high population densities).

Males use horns in contests with rival males over access to tunnels containing females (Emlen 1997a, 2000; Moczek and Emlen 2000; Hunt and Simmons 2002), and large males experience directional selection for increases in horn length because long horns help males win battles (Hunt and Simmons 2001). Small males are relatively ineffective at guarding tunnels and often adopt an alternative, less aggressive tactic: they sneak into guarded tunnels on the sly (Cook 1990; Emlen 1997a; Hunt and Simmons 2000, 2002; Moczek and Emlen 2000). Sperm from small males must compete with sperm from large guarding males (who reside inside tunnels and mate with females more frequently), and in some Onthophagus species, these small males invest disproportionately into testes volume and 

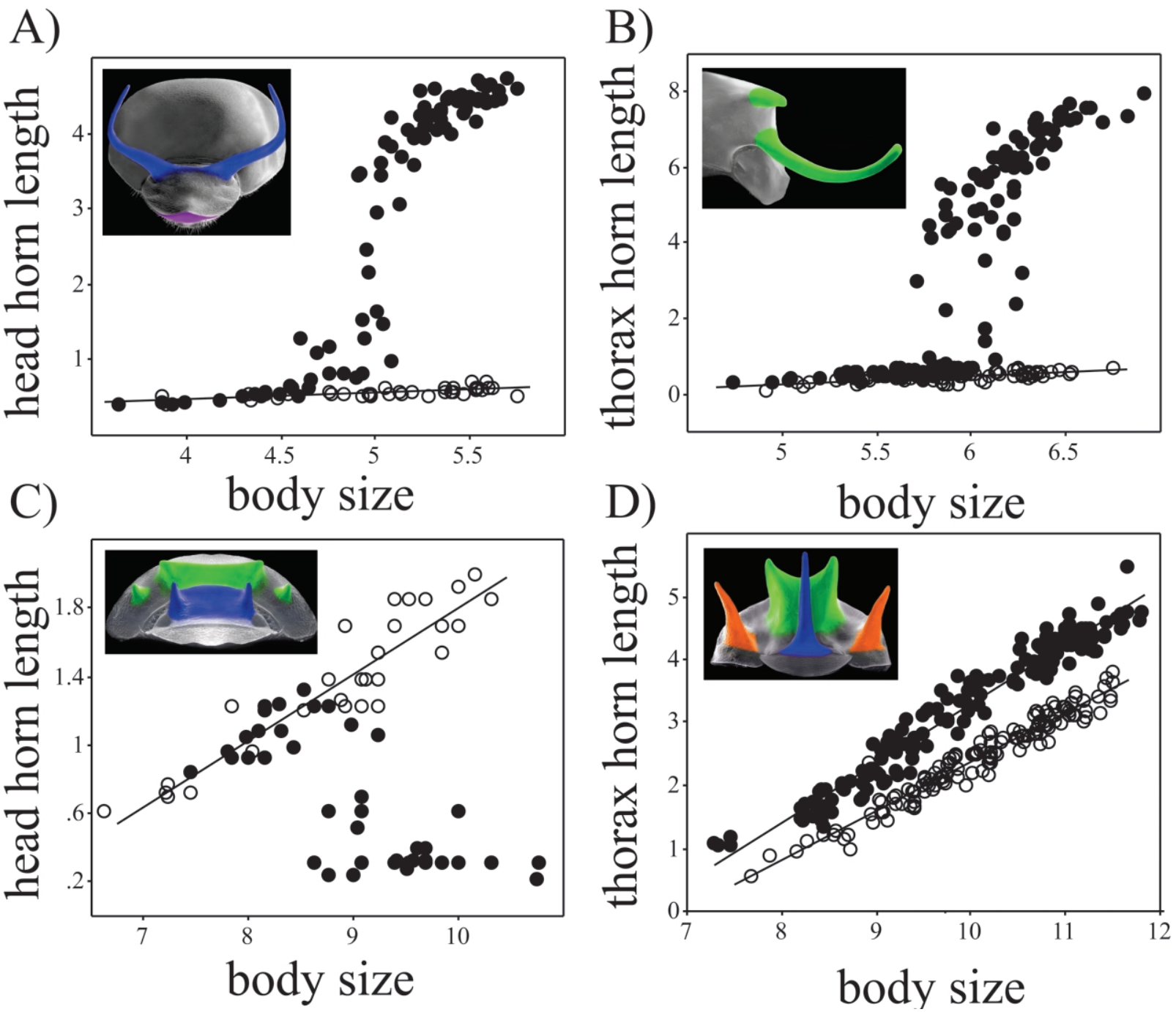

Figure 9: For beetle horns exhibiting dimorphic patterns of expression, the horn lengths of small males and females scale similarly $(A-C)$, suggesting that horn growth in these animals has been reprogrammed in the same direction and to the same extent relative to large males. This pattern holds across horn types (e.g., head horns [H1, blue] in Onthophagus taurus $[A]$ and thorax horns $[\mathrm{H} 4$, green] in O. nigriventris $[B]$ ). It also holds when the polarity of these thresholds has been reversed; in O. sloanei $(C)$, small males and females produce a head horn (H1, blue) not expressed in large males. For beetle horns lacking dimorphism, the horns of small males and females scale differently (e.g., head horns [H1, blue] in O. pentacanthus $[D])$. Solid circles $=$ males; open circles $=$ females.

sperm production (Simmons et al. 1999; Tomkins and Simmons 2000). Recent work suggests that males may be faced with a trade-off between investment in genitalia and horns (Moczek and Nijhout 2004), and horn growth negatively impacts testes mass (L. W. Simmons and D. J. Emlen, unpublished data). Therefore, small males in some environments (e.g., high population densities) may benefit from dispensing with horn production and allocating resources to gamete production.

Thus, horn expression in females and small males is expected to result from different types of selection acting on different classes of individuals, and there is no a priori reason to expect that the direction and nature of these agents of selection should have coincided during the history of this genus. In fact, at least one relevant aspect of the environment (population density) appears to select in opposite directions on these two classes of individuals, favoring females with horns (sexual monomorphism) and small males without horns (male dimorphism).

The striking convergence in evolution of these two phenomena raises the possibility that these changes in patterns of horn expression could be maladapted in at least one of 


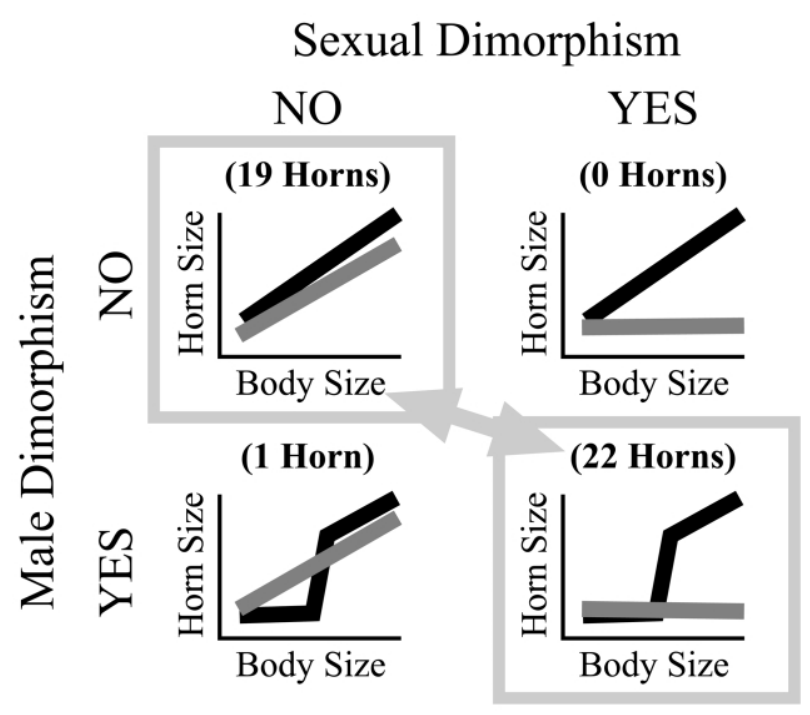

Figure 10: Four possible combinations of male and sexual dimorphism in beetle horn expression. Graphs illustrate representative patterns of scaling for horns exhibiting male monomorphism (top) or male dimorphism (bottom) and sexual monomorphism (left) and sexual dimorphism $($ right $)$. Black bars $=$ males; gray bars $=$ females. None of the 42 horns included in this study were male monomorphic and sexually dimorphic (top right), and only one horn was male dimorphic and sexually monomorphic (bottom left). Nineteen horns were both male and sexually monomorphic (top left); 22 horns were both male and sexually dimorphic (bottom right). All but one of the evolutionary transformations in horn dimorphism involved transitions between these two states.

the two contexts. If these two forms of dimorphism are genetically correlated-linked developmentally and genetically because of shared elements of their endocrine regulatory mechanisms - then changes in one mechanism would necessarily generate corresponding changes in the other, even if the latter were not advantageous.

In fact, these two mechanisms do share at least one critical component of their endocrine regulation: both small males and females use a brief pulse of ecdysteroids to shut off, or "reprogram," proliferation in the cells that will form the horns (Emlen and Nijhout 1999; red arrows, fig. 4). This suggests that these two mechanisms may not be independent of each other. Even though the upstream cues associated with horn expression differ for male dimorphism (nutrition, body size) and sexual dimorphism (genetic factor[s] associated with sex), they both appear to rely on a pulse of the same hormone at the same time to switch the developmental fate of horn cells. If true, then during the history of this genus, any breakdowns that occurred to this component of the regulatory mechanism could have resulted in simultaneous losses of both forms of horn dimorphism.

One prediction from this hypothesis is that the relative lengths of horns in small males and females should be similar. If horn growth in these animals is reprogrammed by the same endocrine event, then the relative amounts of proliferation that do occur in these cells should occur similarly in both small males and females. In fact, the horn lengths of small males and females are similar (i.e., they scale similarly with variation in overall body size). The best illustration of this is again provided by the Australian species $O$. sloanei. In this lineage, both male dimorphism and sexual dimorphism have been lost and then regained, and the polarity of both mechanisms has been reversed; small males and females produce a horn that is not expressed in large males, and the lengths of these horns scale similarly for both small males and females. Consequently, we propose that male dimorphism and sexual dimorphism may have evolved in concert in this genus at least in part because these two phenomena share a critical component of their endocrine regulatory mechanisms.

Cross-sexual transfers of dimorphic mechanisms of trait expression have been proposed for the evolution of male dimorphism in bees (Bego and de Camargo 1984; Kukuk and Schwarz 1988; Danforth 1991) and ants (Yamauchi and Kinomura 1993; Heinze and Trenkle 1997; reviewed in West-Eberhard 2003). In this case, we suggest that male dimorphism in beetle horn expression may have evolved initially through small males co-opting the regulatory mechanism responsible for reprogramming horn growth in females. This would explain both the apparent sharing of an endocrine pulse and the similarity of relative horn sizes of small males and females. Furthermore, it would explain the concerted evolution of these two phenomena: losses of dimorphism in one context occurring simultaneously with losses of dimorphism in the other context.

Although the reverse situation (sexual dimorphism evolving through co-option of an existing mechanism of male dimorphism) could also explain these patterns, we suggest that this latter situation is less likely for two reasons. First, exaggerated morphological structures (e.g., weapons) are generally thought to be more costly for females then they are for males because of potential tradeoffs with fecundity/reproduction (e.g., Fitzpatrick et al. 1995; Martin and Badyaev 1996; Cuervo and Møller 1999). If true, then selection against horn production would have been relatively stronger in females than it was in small males. Second, changes in female horn expression affect the morphology of all females of all body sizes, whereas changes in horn expression in small males affect only a subset of the males. This would have provided a greater opportunity for selection to act on female horns than on the horns of small males (e.g., Roff 1996; West-Eberhard 2003). For these reasons, we suggest that repeated losses of dimorphism in beetle horn expression reflect recurring selection for the expression of female horns, which arose 
through breakdowns in the endocrine mechanism responsible for generating sexual dimorphism in horn expression. Furthermore, we suggest that these gains of female horn expression also resulted in simultaneous losses in the developmental capacity for generating male dimorphism in horn expression. Further studies will be needed to explore the selective consequences of horn expression in both small males and females.

\section{Reconstructing the Evolution of Developmental Mechanisms}

Only rarely is it possible to combine knowledge of how a focal phenotype has changed over time with knowledge of how underlying aspects of the development of that character have changed. Here, we capitalize on existing studies of the hormonal control of horn development in the beetle species $O$. taurus and use this information to inform our comparative study of beetle horn expression. Integrating these research perspectives provides a first glimpse of how two endocrine regulatory mechanisms may have been modified through time to yield the observed transformations in expressed phenotype.

Mapping the presence/absence of dimorphic patterns of horn expression onto our phylogeny suggests the following sequence of events: horns at the base of the head $(\mathrm{H} 1$, blue) appear to have arisen in the immediate ancestor of the tribes Onthophagini, Oniticellini, and Onitini (see "Methods"; Villalba et al. 2002; Philips et al. 2004) as structures exhibiting neither male nor sexual dimorphism; that is, they were expressed to some extent by all individuals. Male and sexual dimorphism in horn expression arose later, apparently after onthophagines had diverged from their sister tribes, but still relatively early in the history of this genus. Once gained, both forms of dimorphism were subsequently lost multiple times, and in one lineage, they appear to have been regained.

Consequently, our data suggest that head horn growth arose as the neutral, or default, pattern of development in Onthophagus beetles and that both male dimorphism and sexual dimorphism were gained later as superimposed levels of developmental control. Horn growth may have been suppressed by an evolutionary gain of a small ecdysteroid pulse at the end of the larval feeding period that inhibited proliferation in horn cells. Coupling the secretion of this hormone pulse with poor nutrition, or with female-specific genetic factors, would have generated male and sexual dimorphism in horn expression.

This historical sequence is biologically plausible for several reasons. First, it is consistent with studies of the endocrine regulation of expression of a number of sexually selected traits, where both males and females share a default developmental trajectory of trait production (e.g., showy male plumage in peacocks and mallards) and where production of the trait is secondarily suppressed in females by secretion of a steroid hormone (these estrogen-dependent mechanisms appear to be the ancestral form of sexual dichromatism in birds; Owens and Short 1995; Kimball and Ligon 1999). Second, it is consistent with phylogenetic studies of fly eye stalks and frog fangs, both of which show early forms of the sexually selected trait expressed in both males and females, and dimorphic trait expression arising later (Emerson 1994; Baker and Wilkinson 2001). Finally, this scenario is consistent with endocrine studies of insect development, which implicate small pulses of steroid hormone in the reprogramming of fates of specific traits (e.g., a small feeding period pulse of ecdysone switches the fate of lepidopteran wing cells so that they initiate pupal rather than larval patterns of gene expression; Kremen and Nijhout 1989).

However, several alternative reconstructions for the evolution of these mechanisms are also possible, and we briefly discuss one important alternative here. What if onthophagine horns are much more ancient structures than we have suggested? If beetle horns arose for the first time in a common ancestor of the dung beetle subfamily Scarabaeinae (approximately 55 million years ago [mya]; 5,000 species) or even as far back as the common ancestor of the superfamily Scarabaeoidea (approximately 160-200 mya; 35,000 species), then the horns of onthophagine dung beetles would be homologous with the horns of rainbow scarabs (genus Phanaeus), rhinoceros beetles (subfamily Dynastinae), and flower beetles (family Cetoniidae).

If horns evolved in any of these more ancient common ancestors, then they would have been lost completely and regained repeatedly in the history of the scarabs. This raises the possibility that the hornless lineage leading to the genus Onthophagus was secondarily hornless; presumably, these beetles would have inherited a default and ancient developmental pattern of horn growth that was already suppressed by an ecdysteroid pulse present in all individuals. The gain (actually a regain) of horns in the immediate ancestor of Onthophagus could then have occurred by an evolutionary loss of secretion of the ecdysteroid pulse, disinhibiting the production of horns. Interestingly, if loss of this pulse occurred only in large males, then a single event could have generated horns, as well as both forms of horn dimorphism, at the same time-they would, in fact, reflect the same event. Although this scenario could explain the simultaneous gain of both male and sexual dimorphism in horn expression, it cannot account for their subsequent patterns of correlated evolution (losses and regains of this pulse always occurring together in both small males and females), especially given the extraordinary evolutionary lability demonstrated by other components of these regulatory mechanisms. 
We draw attention to this alternative possibility because it could mean that the immediate ancestor of Onthophagus possessed horns that were both sexually and male dimorphic, the opposite of what we have assumed for this article. This alternative ancestor state reconstruction could also explain why sexual and male dimorphism occur so frequently across the horned beetles and why so many beetle species bear horns-a question that has haunted biologists for well over a century (e.g., Darwin 1871; Arrow 1951). Fortunately, each of these evolutionary hypotheses makes explicit predictions regarding the endocrine regulation of horn expression in related beetle lineages, and future comparative endocrinological studies should help resolve these questions.

In conclusion, by mapping two forms of dimorphism onto a phylogeny, we begin to reconstruct the evolution of two threshold mechanisms regulating horn development. Our comparative study provides ample evidence of the evolutionary lability that is predicted to arise from the incorporation of thresholds into trait development. But we also see striking evidence of constraint: two phenomena apparently linked both developmentally and evolutionarily as a result of a shared component of their endocrine regulatory mechanisms.

\section{Acknowledgments}

For permission to collect beetles on private property, we thank M. Boggess, B. and S. Hames, N. and L. Henry, J. and H. Hopkins, P. and M. Klopfer, D. Lange, and T. Salisbury. For comments on earlier versions of this manuscript, we thank K. Bright, L. Delph, O. Helmy, J. Losos, T. Mendelson, C. Miller, Q. Szafran, P. (A.) Trillo, D. Zeh, and especially M. J. West-Eberhard. Funding was provided by the National Science Foundation (IBN-0092873 to D.J.E.) and the Australian Research Council (L.W.S.). Beetles were exported from Panama under El Instituto $\mathrm{Na}$ cional de Recursos Naturales Renovables permit 91-98 and from Ecuador under Instituto Ecuatoriano Forestal y de Áreas Naturales y Vida Silvestre permit 045-IC; beetles were imported under USDA Animal and Plant Health Inspection Service permit 45534.

\section{Literature Cited}

Abouheif, E., and G. A. Wray. 2002. Evolution of the gene network underlying wing polyphenism in ants. Science 297:249-252.

Akam, M., P. Holland, P. Ingham, and G. Wray. 1994. The evolution of developmental mechanisms. Company of Biologists, Cambridge.

Alberch, P. 1982. Developmental constraints in evolutionary processes. Pages 313-332 in J. Bonner, ed. Evolution and development. Springer, New York.

Andres, A. J., J. C. Fletcher, F. D. Karim, and C. S. Thummel. 1993. Molecular analysis of the initiation of insect metamorphosis: a comparative study of Drosophila ecdysteroid-regulated transcription. Developmental Biology 160:388-404.

Arrow, G. J. 1951. Horned beetles. W. Junk, The Hague.

Atchley, W. R., and B. K. Hall. 1991. A model for development and evolution of complex morphological structures. Biological Reviews 66:101-157.

Ayoade, O., S. Morooka, and S. Tojo. 1999. Enhancement of short wing formation and ovarian growth in the genetically defined macropterous strain of the brown planthopper, Nilaparvata lugens. Journal of Insect Physiology 45:93-100.

Baker, R. H., and G. S. Wilkinson. 2001. Phylogenetic analysis of sexual dimorphism and eye stalk allometry in stalk-eyed flies (Diopsidae). Evolution 55:1373-1385.

Bego, L. R., and C. A. de Camargo. 1984. On the occurrence of giant males in Nannotrigona (Scaptotrigona) postica Lateille (Hymenoptera, Apidae, Meliponinae). Boletin de Zoologia 8:11-16.

Berger, E. M., K. Goudie, L. Klieger, and R. DeCato. 1992. The juvenile hormone analogue, methoprene, inhibits ecdysterone induction of small heat shock protein gene expression. Developmental Biology 151:410-418.

Bolker, J. A. 2000. Modularity in development and why it matters to evo-devo. American Zoologist 40:770-776.

Bollenbacher, W. E. 1988. The interendocrine regulation of larvalpupal development in the tobacco hornworm, Manduca sexta: a model. Journal of Insect Physiology 34:941-947.

Bonner, J. T. 1982. Evolution and development. Dahlem Konferenzen. Springer, Berlin/Heidelberg and New York.

- 1988. The evolution of complexity. Princeton University Press, Princeton, NJ.

Brakefield, P. M., J. Gates, D. Keys, F. Kesbeke, P. J. Wijngaarden, A. Monteiro, V. French, and S. B. Carroll. 1996. Development, plasticity and evolution of butterfly eyespot patterns. Nature 384:236242.

Brockmann, H. J. 2001. The evolution of alternative strategies and tactics. Advances in the Study of Behavior 30:1-51.

Browder, M. H., L. J. D'Amico, and H. F. Nijhout. 2001. The role of low levels of juvenile hormone esterase in the metamorphosis of Manduca sexta. Journal of Insect Science 1:1-4.

Bryant, P. J. 2001. Growth factors controlling imaginal disc growth in Drosophila. Novartis Foundation Symposia 237:182-199.

Carroll, S. B., J. K. Grenier, and S. D. Weatherbee. 2001. From DNA to diversity: molecular genetics and the evolution of animal design. Blackwell Science, Madison, WI.

Cheverud, J. M. 1984. Quantitative genetics and developmental constraints on evolution by selection. Journal of Theoretical Biology 110:155-171.

- 1996. Developmental integration and the evolution of pleiotropy. American Zoologist 36:44-50.

Cock, A. G. 1966. Genetical aspects of metrical growth and form in animals. Quarterly Review of Biology 41:131-190.

Conlon, I., and M. Raff. 1999. Size control in animal development. Cell 96:235-244.

Connat, J. L., J. P. Delbecque, I. Glitho, and J. Delachambre. 1991. The onset of metamorphosis in Tenebrio molitor larvae (Insecta: Coleoptera) under grouped, isolated and starved conditions. Journal of Insect Physiology 37:653-662.

Conner, J. 1988. Field measurements of natural and sexual selection in the fungus beetle, Bolitotherus cornutus. Evolution 42:736-749.

Cook, D. 1990. Differences in courtship, mating and postcopulatory behaviour between male morphs of the dung beetle Onthophagus 
binodis Thunberg (Coleoptera: Scarabaeidae). Animal Behaviour 40:428-436.

Crowson, R. A. 1981. The biology of the Coleoptera. Academic Press, London.

Cuervo, J. J., and A. P. Møller. 1999. Sex-limited expression of ornamental feathers in birds. Behavioral Ecology 3:246-259.

Cunningham, C. W., K. E. Omland, and T. H. Oakley. 1998. Reconstructing ancestral character states: a critical reappraisal. Trends in Ecology \& Evolution 13:361-366.

Danforth, B. N. 1991. The morphology and behavior of dimorphic males in Perdita portalis (Hymenoptera: Andrenidae). Behavioral Ecology and Sociobiology 29:235-247.

Danforth, B. N., and C. A. Desjardins. 1999. Male dimorphism in Perdita portalis (Hymenoptera, Andrenidae) has arisen from preexisting allometric patterns. Insectes Sociaux 46:18-28.

Darwin, C. 1871. The descent of man and selection in relation to sex. Random House, New York.

Dingle, H. 2002. Hormonal mediation of insect life histories. Pages 237-279 in D. W. Pfaff, A. P. Arnold, A. E. Etgen, S. E. Fahrbach, and R. T. Rubin, eds. Hormones, brain and behavior. Academic Press, San Diego, CA.

Dover, G. 2000. How genomic and developmental dynamics affect evolutionary processes. Bioessays 22:1153-1159.

Eberhard, W. G. 1979. The functions of horns in Podischnus agenor Dynastinae and other beetles. Pages 231-258 in M. S. Blum and N. A. Blum, eds. Sexual selection and reproductive competition in insects. Academic Press, New York.

1980. Horned beetles. Scientific American 242:166-182.

- 1987. Use of horns in fights by the dimorphic males of Ageopsis nigricollis (Coleoptera, Scarabaeidae, Dynastinae). Journal of the Kansas Entomological Society 60:504-509.

Eberhard, W. G., and E. Gutierrez. 1991. Male dimorphism in beetles and earwigs and the question of developmental constraints. Evolution 45:18-28.

Edgar, B. A. 1999. From small flies come big discoveries about size control. Nature Cell Biology 1:E191-E193.

Emerson, S. B. 1994. Testing pattern predictions of sexual selection: a frog example. American Naturalist 143:848-869.

Emlen, D. J. 1994. Environmental control of horn length dimorphism in the beetle Onthophagus acuminatus (Coleoptera: Scarabaeidae). Proceedings of the Royal Society of London B 256:131-136.

- 1996. Artificial selection on horn length-body size allometry in the horned beetle Onthophagus acuminatus (Coleoptera: Scarabaeidae). Evolution 50:1219-1230.

. 1997a. Alternative reproductive tactics and male dimorphism in the horned beetle Onthophagus acuminatus (Coleoptera: Scarabaeidae). Behavioral Ecology and Sociobiology 41:335-341.

. 1997b. Diet alters male horn allometry in the beetle Onthophagus acuminatus (Coleoptera: Scarabaeidae). Proceedings of the Royal Society of London B 264:567-574.

- 2000. Integrating development with evolution: a case study with beetle horns. BioScience 50:403-418.

. 2001. Costs and the diversification of exaggerated animal structures. Science 291:1534-1536.

- 2005. The role of genes and the environment in the expression and evolution of animal alternative tactics. In R. Oliveira, M. Taborsky, and H. J. Brockmann, eds. Alternative reproductive tactics: an integrative approach. Cambridge University Press (forthcoming).

Emlen, D. J., and C. E. Allen. 2004. Genotype to phenotype: phys- iological control of trait size and scaling in insects. Integrative and Comparative Biology 43:617-634.

Emlen, D. J., and H. F. Nijhout. 1999. Hormonal control of male horn length dimorphism in the horned beetle Onthophagus taurus. Journal of Insect Physiology 45:45-53.

- 2000. The development and evolution of exaggerated morphologies in insects. Annual Review of Entomology 45:661-708.

- 2001. Hormonal control of male horn length dimorphism in the dung beetle Onthophagus taurus (Coleoptera: Scarabaeidae): a second critical period of sensitivity to juvenile hormone. Journal of Insect Physiology 47:1045-1054.

Emlen, D. J., J. Marangelo, B. Ball, and C. W. Cunningham. 2005. Diversity in the weapons of sexual selection: horn evolution in the beetle genus Onthophagus. Evolution 59:1060-1084.

Enrödi, S. 1985. The Dynastinae of the world. W. Junk, Boston.

Evans, J. D., and D. E. Wheeler. 2001. Gene expression and the evolution of insect polyphenisms. Bioessays 23:62-68.

Fabre, J. H. 1899. Souvenirs Entomologiques, Paris. Excerpts translated by A. T. de Mattos. Hodder \& Stoughton, London.

Fitzpatrick, S., A. Berglund, and G. Rosenqvist. 1995. Ornaments or offspring: costs to reproductive success restrict sexual selection processes. Biological Journal of the Linnean Society 55:251-260.

Fristrom, D., and J. W. Fristrom. 1993. The metamorphic development of the adult epidermis. Pages 843-897 in M. Bate and A. Martinez-Arias, eds. The development of Drosophila melanogaster. Cold Spring Harbor Laboratory Press, Plainview, NY.

Gilbert, L. I. 1989. The endocrine control of molting: the tobacco hornworm, Manduca sexta, as a model system. Pages 448-471 in J. Koolman, ed. Ecdysone: from chemistry to mode of action. Thieme, Stuttgart.

Gilbert, L. I., R. Rybczynski, and S. Tobe. 1996. Endocrine cascade in insect metamorphosis. Pages 60-108 in L. I. Gilbert, J. R. Tata, and B. G. Atkinson, eds. Metamorphosis: postembryonic reprogramming of gene expression in amphibian and insect cells. Academic Press, San Diego, CA.

Goldsmith, S. K. 1987. The mating system and alternative reproductive behaviors of Dendrobias mandibularis (Coleoptera: Cerambycidae). Behavioral Ecology and Sociobiology 20:111-115.

Greene, E. 1989. A diet induced developmental polymorphism in a caterpillar. Science 243:643-646.

1999. Phenotypic variation in larval development and evolution: polymorphism, polyphenism, and developmental reaction norms. Pages 379-410 in M. Wake and B. Hall, eds. The origin and evolution of larval forms. Academic Press, New York.

Gross, M. R. 1996. Alternative reproductive strategies and tactics: diversity within sexes. Trends in Ecology \& Evolution 11:92-98.

Halffter, G., and W. G. Edmonds. 1982. The nesting behavior of dung beetles (Scarabaeidae): an ecological and evolutive approach. Instituto de Ecologica, Federal District, Mexico.

Halffter, G., and E. G. Matthews. 1966. The natural history of the dung beetles of the subfamily scarabaeinae (Coleoptera: Scarabaeidae). Folia Entomologica Mexicana 12-14:1-313.

Hall, B. K. 1992. Evolutionary developmental biology. Chapman \& Hall, London.

Hanken, J., and P. Thorogood. 1993. Evolution and development of the vertebrate skull: the role of pattern formation. Trends in Ecology \& Evolution 8:9-15.

Hanley, R. S. 2001. Mandibular allometry and male dimorphism in a group of obligately mycophagous beetles (Insecta: Coleoptera: 
Staphylinidae). Biological Journal of the Linnean Society 72:451459.

Hardie, J., and A. D. Lees. 1985. Endocrine control of polymorphism and polyphenism. Pages 441-489 in G. A. Kerkut and L. I. Gilbert, eds. Comprehensive insect physiology, biochemistry and pharmacology. Vol. 8. Pergamon, Oxford.

Harrison, R. G. 1979. Flight polymorphism in the field cricket Gryllus pennsylvannicus. Oecologia (Berlin) 40:125-132.

. 1980. Dispersal polymorphism in insects. Annual Review of Ecology and Systematics 11:95-118.

Hartfelder, K. 1990. Regulatory steps in caste development of eusocial bees. Pages 245-264 in W. Engels, ed. Social insects: an evolutionary approach to castes and reproduction. Springer, Heidelberg.

Hartfelder, K., and D. J. Emlen. 2004. Endocrine control of insect polyphenism. Comprehensive Molecular Insect Science 3:651-703.

Hartfelder, K., and W. Engels. 1998. Social insect polymorphism: hormonal regulation of plasticity in development and reproduction in the honeybee. Current Topics in Developmental Biology 40:45-77.

Hazel, W. N. 1995. The causes and evolution of phenotypic plasticity in pupal color in swallowtail butterflies. Pages 205-210 in J. M. Scriber, Y. Tsubaki, and R. C. Lederhouse, eds. Swallowtail butterflies: their ecology and evolutionary biology. Scientific Publishers, Gainesville, FL.

Hazel, W. N., R. Smock, and M. D. Johnson. 1990. A polygenic model for the evolution and maintenance of conditional strategies. Proceedings of the Royal Society of London B 242:181-187.

Heinze, J., and S. Trenkle. 1997. Male polymorphism and gynandromorphs in the ant Cardiocondyla emeryi. Naturwissenschaften 84:129-131.

Hews, D. K., and M. C. Moore. 1995. Influence of androgens on differentiation of secondary sex characters in tree lizards, Urosaurus ornatus. General and Comparative Endocrinology 97:86-102.

Huet, C. 1980. Évolution des ébauches genitals présomptives de Tenebrio molitor chez des gynandromorphes expérimentaux: indépendance vis-á-vis de l'environnement tissulaire et hormonal. Comptes Rendus de l'Academie des Sciences Série D 290:987-990.

Hunt, J., and L. W. Simmons. 1997. Patterns of fluctuating asymmetry in beetle horns: an experimental examination of the honest signaling hypothesis. Behavioral Ecology and Sociobiology 41:109_ 114 .

. 1998. Patterns of paternal provisioning covary with male morphology in a horned beetle (Onthophagus taurus) (Coleoptera: Scarabaeidae). Behavioral Ecology and Sociobiology 41:109-114.

. 2000. Maternal and paternal effects on offspring phenotype in the dung beetle Onthophagus taurus. Evolution 54:936-941.

. 2001. Status-dependent selection in the dimorphic beetle Onthophagus taurus. Proceedings of the Royal Society of London B 268:2409-2414.

2002. The genetics of maternal care: direct and indirect genetic effects on phenotype in the dung beetle Onthophagus taurus. Proceedings of the National Academy of Sciences of the USA 99:6828-6832.

Hunt, J., L. W. Simmons, and J. S. Kotiaho. 2002. A cost of maternal care in the dung beetle Onthophagus taurus? Journal of Evolutionary Biology 15:57-64.

Iwanaga, K., and S. Tojo. 1986. Effects of juvenile hormone and rearing density on wing dimorphism and oocyte development in the brown planthopper Nilaparvata lugens. Journal of Insect Physiology 32:585-590.
Jockusch, E. L., C. Nulsen, S. J. Newfeld, and L. M. Nagy. 2000. Leg development in flies versus grasshoppers: differences in $d p p$ expression do not lead to differences in the expression of downstream components of the leg-patterning pathway. Development 127: $1617-1626$.

Johnston, L. A., and P. Gallant. 2002. Control of growth and organ size in Drosophila. Bioessays 24:54-64.

Kawamura, K., T. Shibata, O. Saget, D. Peel, and P. J. Bryant. 1999. A new family of growth factors produced by the fat body and active on Drosophila imaginal disc cells. Development 126:211219 .

Kawano, K. 1995a. Habitat shift and phenotypic character displacement in sympatry of two closely related rhinoceros beetle species (Coleoptera: Scarabaeidae). Annals of the Entomological Society of America 88:641-652.

- 1995b. Horn and wing allometry and male dimorphism in giant rhinoceros beetles (Coleoptera: Scarabaeidae) of tropical Asia and America. Annals of the Entomological Society of America 88: 92-99.

Kimball, R. T., and J. D. Ligon. 1999. Evolution of avian plumage dichromatism from a proximate perspective. American Naturalist 154:182-193.

Kirschner, M., and J. Gerhart. 1998. Evolvability. Proceedings of the National Academy of Sciences of the USA 95:8420-8427.

Kotiaho, J. S., and J. L. Tomkins. 2001. The discrimination of alternative male morphologies. Behavioral Ecology 12:553-557.

Kotiaho, J. S., L. W. Simmons, J. Hunt, and J. L. Tomkins. 2003. Males influence maternal effects that promote sexual selection: a quantitative genetic experiment with dung beetles Onthophagus taurus. American Naturalist 161:852-859.

Kremen, C., and H. F. Nijhout. 1989. Juvenile hormone controls the onset of pupal commitment in the imaginal disks and epidermis of Precis coenia (Lepidoptera, Nymphalidae). Journal of Insect Physiology 35:603-612.

Kukuk, P. F., and M. Schwarz. 1988. Macrocephalic male bees as functional reproductives and possible guards. Pan-Pacific Entomologist 64:131-137.

LaBarbera, M. 1989. Analyzing body size as a factor in ecology and evolution. Annual Review of Ecology and Systematics 20:97-117.

Lailvaux, S. P., J. Hathway, J. Pomfret, and R. J. Knell. 2005. Horn size predicts physical performance in the beetle Euoniticellus intermedius (Coleoptera: Scarabaeidae). Functional Ecology (forthcoming).

Losos, J. B. 1999. Uncertainty in the reconstruction of ancestral character states and limitations on the use of phylogenetic comparative methods. Animal Behaviour 58:1319-1324.

Lüscher, M. 1960. Hormonal control of caste differentiation in termites. Annals of the New York Academy of Sciences 89:549-563.

Maddison, W. P. 1990. A method for testing the correlated evolution of two binary characters: are gains or losses concentrated on certain branches of a phylogenetic tree? Evolution 44:539-557.

Maddison, W. P., and D. R. Maddison. 1999. MacClade: analysis of phylogeny and character evolution. Version 3.08a. Sinauer, Sunderland, MA.

Main, H. 1922. Notes on the metamorphosis of Onthophagus taurus L. Proceedings of the Entomological Society of London 1922:1416.

Martin, T. E., and A. V. Badyaev. 1996. Sexual dichromatism in birds: importance of nest predation and nest location for females versus males. Evolution 50:2454-2460. 
Matthews, E. G. 1972. A revision of the scarabaeine dung beetles of Australia. Australian Journal of Zoology 9(suppl.):1-330.

Milan, M., S. Campuzano, and A. Garcia-Bellido. 1996. Cell cycling and patterned cell proliferation in the wing primordium of Drosophila. Proceedings of the National Academy of Sciences of the USA 93:640-645.

Miura, T. 2001. Morphogenesis and gene expression in the soldiercaste differentiation of termites. Insectes Sociaux 48:216-223.

Moczek, A. P. 1998. Horn polyphenism in the beetle Onthophagus taurus: larval diet quality and plasticity in parental investment determine adult body size and male horn morphology. Behavioral Ecology 9:636-642.

. 2002. Allometric plasticity in a polyphenic beetle. Ecological Entomology 27:58-67.

Moczek, A. P., and D. J. Emlen. 1999. Proximate determination of male horn dimorphism in the beetle Onthophagus taurus (Coleoptera: Scarabaeidae). Journal of Evolutionary Biology 12:27-37.

- 2000. Male horn dimorphism in the scarab beetle, Onthophagus taurus: do alternative reproductive tactics favour alternative phenotypes? Animal Behaviour 59:459-466.

Moczek, A. P., and H. F. Nijhout. 2002. Developmental mechanisms of threshold evolution in a polyphenic beetle. Evolution and Development 4:252-264.

- 2003. Rapid evolution of a polyphenic threshold. Evolution and Development 5:259-268.

- 2004. Trade-offs during the development of primary and secondary sexual traits in a dimorphic beetle. American Naturalist 163:184-191.

Moczek, A. P., J. Hunt, D. J. Emlen, and L. W. Simmons. 2002. Threshold evolution in exotic populations of a polyphonic beetle. Evolutionary Ecology Research 4:587-601.

Moore, M. C. 1991. Application of organization-activation theory to alternative male reproductive strategies: a review. Hormones and Behavior 25:154-179.

Moran, N. A. 1992. The evolutionary maintenance of alternative phenotypes. American Naturalist 139:971-989.

Moura, R. C., M. J. Souza, and A. C. Lira-Neto. 2003. Karyotypic characterization of representatives from Melolonthinae (Coleoptera: Scarabaeidae): karyotypic analysis, banding and fluorescent in situ hybridization (FISH). Hereditas 138:200-206.

Needham, J. 1933. On the dissociability of the fundamental processes in ontogenesis. Biological Reviews 8:180-233.

Nijhout, H. F. 1994. Insect hormones. Princeton University Press, Princeton, NJ.

- 1999a. Control mechanisms of polyphenic development in insects. BioScience 49:181-192.

. 1999b. Hormonal control in larval development and evolution: insects. Pages 218-254 in B. K. Hall and M. H. Wake, eds. The origin and evolution of larval forms. Academic Press, New York.

Nijhout, H. F., and L. W. Grunert. 2003. Bombyxin is a growth factor for wing imaginal disks in Lepidoptera. Proceedings of the National Academy of Sciences of the USA 99:15446-15450.

Nijhout, H. F., and D. E. Wheeler. 1982. Juvenile hormone and the physiological basis of insect polymorphisms. Quarterly Review of Biology 57:109-133.

- 1996. Growth models of complex allometries in holometabolous insects. American Naturalist 148:40-56.

Noirot, C., and J. M. Pasteels. 1987. Ontogenetic development and evolution of the worker caste in termites. Experientia 43:851-860.
Otronen, M. 1988. Intra- and intersexual interactions at breeding burrows in the horned beetle, Coprophaneus ensifer. Animal Behaviour 36:741-748.

Owens, I. P. F., and R. V. Short. 1995. Hormonal basis of sexual dimorphism in birds: implications for new theories of sexual selection. Trends in Ecology \& Evolution 10:44-47.

Paulian, R. 1935. Le polymorphisme des males de Coléopteres. Pages 1-33 in G. Tessier, ed. Exposés de biométrie et statistique biologique. IV. Actualités scientifiques et industrielles 255. Hermann, Paris.

Philips, T. K., E. Pretorius, and C. H. Scholtz. 2004. A phylogenetic analysis of dung beetles (Scarabaeinae: Scarabaeidae): unrolling an evolutionary history. Invertebrate Systematics 18:53-88.

Pigliucci, M., C. Schlichting, C. Jones, and K. Schwenk. 1996. Developmental reaction norms: the interactions among allometry, ontogeny and plasticity. Plant Species Biology 11:69-85.

Quennedey, A., and B. Quennedey. 1990. Morphogenesis of the wing anlagen in the mealworm beetle Tenebrio molitor during the last larval instar. Tissue and Cell 22:721-740.

Rachinsky, A., and K. Hartfelder. 1990. Corpora allata activity, a prime regulating element for caste-specific juvenile hormone titre in honey bee larvae (Apis mellifera carnica). Journal of Insect Physiology 36:189-194.

Raff, R. A. 1996. The shape of life. University of Chicago Press, Chicago.

Raff, R. A., and T. C. Kaufman. 1983. Embryos, genes, and evolution. Indiana University Press, Bloomington.

Raff, R. A., and B. J. Sly. 2000. Modularity and dissociation in the evolution of gene expression territories in development. Evolution and Development 2:102-113.

Rankin, S. M., J. Chambers, and J. P. Edwards. 1997. Juvenile hormone in earwigs: roles in oogenesis, mating, and maternal behaviors. Archives of Insect Biochemistry and Physiology 35:427442.

Rasmussen, J. 1994. The influence of horn and body size on the reproductive behavior of the horned rainbow scarab beetle Phanaeus difformis (Coleoptera: Scarabaeidae). Journal of Insect Behaviour 7:67-82.

Riddiford, L. M. 1994. Cellular and molecular actions of juvenile hormone. I. General considerations and premetamorphic actions. Advances in Insect Physiology 24:213-274.

-1996. Molecular aspects of juvenile hormone action in insect metamorphosis. Pages 223-253 in L. I. Gilbert, J. R. Tata, and B. G. Atkinson, eds. Metamorphosis: postembryonic reprogramming of gene expression in amphibian and insect cells. Academic Press, San Diego, CA.

Riska, B. 1986. Some models for development, growth, and morphometric correlation. Evolution 40:1303-1311.

Roff, D. A. 1986. The genetic basis of wing dimorphism in the sand cricket, Gryllus firmus and its relevance to the evolution of wing dimorphism in insects. Heredity 57:221-231.

- 1994. The evolution of dimorphic traits: predicting the genetic correlation between environments. Genetics 136:395-401.

. 1996. The evolution of threshold traits in animals. Quarterly Review of Biology 71:3-35.

Rowland, J. M. 2003. Male horn dimorphism, phylogeny and systematics of rhinoceros beetles of the genus Xylotrupes (Scarabaeidae: Coleoptera). Australian Journal of Zoology 51:213-258.

Schlosser, G., and G. P. Wagner. 2004. Modularity in development and evolution. University of Chicago Press, Chicago. 
Schulz, D. J., J. P. Sullivan, and G. E. Robinson. 2002. Juvenile hormone and octopamine in the regulation of division of labor in honey bee colonies. Hormones and Behavior 42:222-231.

Simmons, L. W., J. L. Tomkins, and J. Hunt. 1999. Sperm competition games played by dimorphic male beetles. Proceedings of the Royal Society of London B 266:145-150.

Siva-Jothy, M. T. 1987. Mate securing tactics and the costs of fighting in the Japanese horned beetle, Allomyrina dichotoma L (Scarabaeidae). Journal of Etholology 5:165-172.

Starnecker, G., and W. Hazel. 1999. Convergent evolution of neuroendocrine control of phenotypic plasticity in pupal color in butterflies. Proceedings of the Royal Society of London B 266:24092412.

Stern, D. 2003. Body-size control: how an insect knows it has grown enough. Current Biology 13:R267-R269.

Stern, D. L. 2000. Perspective: evolutionary developmental biology and the problem of variation. Evolution 54:1079-1091.

Stern, D. L., and D. J. Emlen. 1999. The developmental basis for allometry in insects. Development 126:1091-1101.

Stern, D. L., and W. A. Foster. 1996. The evolution of soldiers in aphids. Biological Reviews of the Cambridge Philosophical Society 71:27-79.

Stern, D. L., A. Moon, and C. Martinez del Rio. 1996. Caste allometries in the soldier-producing aphid Pseudoregma alexanderi (Hormaphididae: Aphidoidea). Insectes Sociaux 43:137-147.

Strambi, A., C. Strambi, P.-F. Röseler, and I. Röseler. 1984. Simultaneous determination of juvenile hormone and ecdysteroid titers in the hemolymph of bumblebee prepupae (Bombus hypnorum and B. terrestris). General and Comparative Endocrinology 55:8388.

Svácha, P. 1992. What are and what are not imaginal discs: re-evaluation of some basic concepts (Insect, Holometabola). Developmental Biology 154:101-117.

Tomkins, J. L., and L. W. Simmons. 1996. Dimorphisms and fluctuating asymmetry in the forceps of male earwigs. Journal of Evolutionary Biology 9:753-770.

. 2000. Sperm competition games played by dimorphic male beetles: fertilization gains with equal mating access. Proceedings of the Royal Society of London B 267:1547-1553.

Tomkins, J. L., J. S. Kotiaho, and N. R. LeBas. 2005. Matters of scale: positive allometry and the evolution of male dimorphisms. American Naturalist 165:389-402.

Truman, J. W., and L. M. Riddiford. 1999. The origins of insect metamorphosis. Nature 401:447-452.

. 2002. Endocrine insights into the evolution of metamorphosis in insects. Annual Review of Entomology 47:467-500.

Tu, M.-P., and M. Tatar. 2003. Juvenile diet restriction and the aging and reproduction of adult Drosophila melanogaster. Aging Cell 2: 327-333.

Venu, G., G. Venkatachalaiah, and A. Kumar. 2000. Chromosomal analysis of three species of South Indian beetles (Coleoptera, Scarabaeidae). Journal of Cytology and Genetics 1:67-70.

Villalba, S., J. M. Lobo, F. Martín-Piera, and R. Zardoya. 2002. Phylogenetic relationships of Iberian dung beetles (Coleoptera: Scarabaeinae): insights on the evolution of nesting behavior. Journal of Molecular Evolution 55:116-126.
Von Dassow, G., and R. Munro. 1999. Modularity in animal development and evolution: elements of a conceptual framework for evo-devo. Journal of Experimental Zoology 285:307-325.

Von Dassow, G., E. Meir, E. M. Munro, and G. M. Odell. 2000. The segment polarity network is a robust developmental module. Nature 406:188-192.

Wagner, G. P. 1996. Homologues, natural kinds, and the evolution of modularity. American Zoologist 36:36-43.

Wagner, G. P., and L. Altenberg. 1996. Perspective: complex adaptations and the evolution of evolvability. Evolution 50:967-976.

Weinkove, D., and S. J. Leevers. 2000. The genetic control of organ growth: insights from Drosophila. Current Opinion in Genetics and Development 10:75-80.

West-Eberhard, M. J. 1989. Phenotypic plasticity and the origins of diversity. Annual Review of Ecology and Systematics 20:249-278.

. 1992. Behavior and evolution. Pages 57-76 in P. R. Grant and H. S. Horn, eds. Molds, molecules and metazoa: growing points in evolutionary biology. Princeton University Press, Princeton, NJ.

2003. Developmental plasticity and evolution. Oxford University Press, Oxford.

Wheeler, D. E. 1991. The developmental basis of worker caste polymorphism in ants. American Naturalist 138:1218-1238.

Wheeler, D. E., and H. F. Nijhout. 1983. Soldier determination in Pheidole bicarinata: effect of methoprene on caste and size within castes. Journal of Insect Physiology 29:847-854.

Wilkinson, G. S. 1993. Artificial selection alters allometry in the stalkeyed fly Cyrtodiopsis dalmanni (Diptera: Diopsidae). Genetics Research 62:213-222.

Williams, C. 1980. Growth in insects. Pages 369-383 in M. Locke and D. S. Smith, eds. Insect biology in the future. Academic Press, New York.

Williams, T. A., and L. M. Nagy. 2001. Developmental modularity and the evolutionary diversification of arthropod limbs. Journal of Experimental Zoology (Molecular Developmental Evolution) 291:241-257.

Wilson, E. O. 1953. The origin and evolution of polymorphism in ants. Quarterly Review of Biology 28:136-156.

- 1971. The insect societies. Belknap/Harvard University Press, Cambridge, MA.

Yamauchi, K., and K. Kinomura. 1993. Lethal fighting and reproductive strategies of dimorphic males in Cardiocondyla ants (Hymenoptera: Formicidae). Pages 373-402 in T. Inoue and S. Yamane, eds. Evolution of insect societies. Hakuhinsha, Tokyo.

Zeh, D. W., and J. A. Zeh. 1992. Sexual selection and sexual dimorphism in the harlequin beetle Acrocinus longimanus. Biotropica 24:86-96.

Zera, A. J., and R. F. Denno. 1997. Physiology and ecology of dispersal polymorphism in insects. Annual Review of Entomology 42:207231.

Zera, A. J., and C. L. Holtmeier. 1992. In vivo and in vitro degradation of juvenile hormone-III in presumptive long-winged and shortwinged Gryllus rubens. Journal of Insect Physiology 38:61-74.

Symposium Editor: Lynda Delph 